ISSN 2079-3200

www.mdpi.com/journal/jintelligence

Article

\title{
Can GE-Covariance Originating in Phenotype to Environment Transmission Account for the Flynn Effect?
}

\section{Janneke M. de Kort ${ }^{1, *}$, Conor V. Dolan ${ }^{1}$, Kees-Jan Kan ${ }^{1,2}$, Catharina E. M. van Beijsterveldt ${ }^{1,3}$, Meike Bartels ${ }^{1,3,4}$ and Dorret I. Boomsma ${ }^{1,3,4}$}

1 Department of Biological Psychology, VU University, van der Boechorststraat 1, 1081 BT Amsterdam, The Netherlands; E-Mails: c.v.dolan@vu.nl (C.V.D.); k.j.kan@vu.nl (K.-J.K.); c.e.m.van.beijsterveldt@vu.nl (C.E.M.B.); m.bartels@vu.nl (M.B.);

d.i.boomsma@vu.nl (D.I.B.)

2 Department of Methods, VU University, van der Boechorststraat 1, 1081 BT Amsterdam, The Netherlands

3 EMGO+ Institute for Health and Care, van der Boechorststraat 7, 1081 BT Amsterdam, The Netherlands

4 Neuroscience Campus Amsterdam (NCA), de Boelelaan 1085, 1081 HV Amsterdam, The Netherlands

* Author to whom correspondence should be addressed; E-Mail: j.m.de.kort@vu.nl; Tel.: +31-20-5986332; Fax: +31-20-5988832.

Received: 10 February 2014; in revised form: 20 August 2014 / Accepted: 21 August 2014 / Published: 1 September 2014

\begin{abstract}
The Dickens and Flynn model of the Flynn effect (generational increases in mean IQ) assigns an important role to genotype-environment covariance (GE-cov). We quantify GE-cov in a longitudinal simplex model by modeling it as phenotype to environment $(\mathrm{Ph}->\mathrm{E})$ transmission in twin data. The model fits as well as the standard genetic simplex model, which assumes uncorrelated genetic and environmental influences. We use the results to explore numerically the possible role of GE-cov in amplifying increases in environmental means. Given the estimated $\mathrm{Ph}->\mathrm{E}$ transmission parameters, GE-cov resulted in an amplification (in std units) of a factor 1.57 (full scale IQ) to 1.7 (performance IQ). The results lend credence to the role of GE-cov in the Flynn effect.
\end{abstract}


Keywords: genotype-environment covariance; Flynn effect; Dickens and Flynn model; longitudinal genetic modeling

\section{Introduction}

Dickens and Flynn [1] proposed an elaborate model to account for the Flynn (a.k.a., Lynn-Flynn) effect, i.e., increases in average of psychometric measures of cognitive ability in the order of $2 / 3$ of one standard deviation per 30 years (10 points given a standard deviation of 15) [2,3]. Their model combines changes in environmental means within a developmental process, which gives rise to genotype-environment covariance (GE-cov). Such covariance is consistent with theoretical notions concerning the interplay of genotype and environment in cognitive development [4-6,7]. These include the matching of genetic and environmental influences due to passive GE-cov (the child's environment being a function of the parental intelligence), and active GE-cov(the developing child creating or choosing environments matching his or her intelligence). While in theory, GE-cov is considered to be relevant to cognitive development, in the actual modeling of intelligence in genetically informative samples (e.g., twins), the analyses are usually based on the assumption of uncorrelated genetic and environmental effects. This is notably the case in longitudinal and multivariate modeling within the classical twin design, although the estimation of GE-cov has been considered in extended family and twin designs [8-11].

Given the relevance of GE-cov to the Dickens and Flynn (D\&F) model, and to cognitive development in general, the aim of the present paper is to model GE-cov in intelligence by means of phenotype to environment $(\mathrm{Ph}->\mathrm{E})$ transmission in longitudinal twin data. $\mathrm{Ph}->\mathrm{E}$ transmission implies that the phenotype (cognitive ability) at time $\mathrm{t}\left(\mathrm{Ph}_{\mathrm{t}}\right)$ is predictive of environmental (relevant to the phenotype) influences at time $\mathrm{t}+1, \mathrm{E}_{\mathrm{t}+1}$. The direct regression of $\mathrm{E}_{\mathrm{t}+1}$ on $\mathrm{Ph}_{\mathrm{t}}$ is compatible with active and passive GE-cov. Ph->E transmission gives rise to the correlation of genetic influences at time $t$ with the environmental influences at time $t+1$, through the mediation of the phenotype at time $t$. Dickens and Flynn considered the influence of GE-cov in four different effects: Matching, averaging, and multiplication either within the individual, or within the social context [1]. The former three pertain to the individual environment, whereas the latter pertains to the social environment. The longitudinal twin model presented below includes the effects of matching, averaging and multiplication, but does not include the social multiplier. However the proposed model does have the virtue of being operational, i.e., it can be applied to longitudinal twin data. Fitting the model provides empirical estimates of GE-cov representative of Dutch children born between 1985 and 1996, and so shines some light on the plausibility of the essential role of GE-cov within the Dickens and Flynn model. Furthermore, using the results obtained, we can assess the degree to which hypothetical changes in environmental (latent) means and $\mathrm{Ph}->\mathrm{E}$ transmission parameters account for the Flynn effect. Specifically, we determine the degree to which increases in the latent environmental means in combination with changes in $\mathrm{Ph}-\mathrm{E}$ transmission parameters give rise to changes in phenotypic means. The changes in environmental means are supposed to be due to environmental improvements relevant to the development of cognitive abilities (these may in principle include social multiplier effects). 
The outline of this paper is as follows. We first present two competing models, the standard ACE simplex, comprising additive genetic (A), common or shared (by twins) environmental effects (C), and unshared environmental effects $(\mathrm{E})$ and the extended AE simplex which includes $\mathrm{Ph}->\mathrm{E}$ transmission. Here, we explain how our conceptualization of $\mathrm{Ph}->\mathrm{E}$ transmission is in line with the concept of matching as proposed by Dickens and Flynn [1]. Second, we present the results of fitting these competing models to full scale IQ (FSIQ) and performance IQ (perfIQ) data observed at four repeated occasions in monozygotic (MZ) and dizygotic (DZ) twins. We fit a standard genetic simplex model to the data [12-14], to assess the goodness of fit of this model. We call this the standard model as, like most applications of genetic covariance structure modeling to intelligence data, it does not include GE-cov. The phenotypic covariance structure is subjected to an orthogonal decomposition into uncorrelated additive genetic and shared and unshared environmental components. Subsequently, we fit the alternative model, based on the simplex model, but including $\mathrm{Ph}-\mathrm{E}$ transmission. This model includes additive genetic and environmental effects. $\mathrm{Ph}-\mathrm{P}$ transmission results in GE-cov and correlated environment, which differs from the correlated environment due to shared environmental influences. We assess the goodness of fit of the alternative model in the light of the standard model, as it is important to establish that our alternative model fits adequately, relative to this standard model. Thirdly, we extend the AE model to include environmental means. We explain how the relation between the environmental means in combination with $\mathrm{Ph}->\mathrm{E}$ transmission is in line with Dickens and Flynn's notion of the multiplier [1]. To explore the degree to which changes in environmental means, in combination with changes in $\mathrm{Ph}->\mathrm{E}$ transmission parameters, can contribute to the Flynn effect, we use the parameters of the AE model, as plausible values. We conclude the paper with a discussion.

\section{Longitudinal Genetic Modeling}

\subsection{The Standard ACE Simplex Model Applied to Twin Data}

Genetic covariance structure modeling (GCSM) involves the decomposition of the phenotypic covariance matrix into genetic and environmental covariance matrices, which are simultaneously subject to covariance structure modeling $[9,15]$. In most applications of GCSM within the classical twin design (involving MZ and DZ twins), the decomposition is orthogonal in the sense that the genetic and environmental sources of phenotypic differences are uncorrelated. This model is depicted in Figure 1. To ease model specification into a time specific part and the longitudinal model, let $y_{i t}$ denote the FSIQ or perfIQ test score of twin member $\mathrm{i}(\mathrm{i}=1,2)$ at time $\mathrm{t}(\mathrm{t}=1, \ldots, \mathrm{T}$; indexed by age, see below), where the phenotype $\mathrm{y}_{\mathrm{it}}$ is decomposed into a part, $\mathrm{y}^{*}{ }_{\mathrm{i}}$, that is subject to the longitudinal model, and the time specific part, $z_{i t}$, which may include zero mean occasion specific influences

$$
y_{i t}=\beta_{0 \mathrm{t}}+y^{*}{ }_{i t}+z_{i t}
$$

where $\beta_{0 t}$ is the phenotypic mean at time t. The score $z_{i t}$ is a zero mean time specific residual, which is subject to its own decomposition:

$$
\mathrm{z}_{\mathrm{it}}=\mathrm{a}_{\mathrm{it}}+\mathrm{c}_{\mathrm{it}}+\mathrm{e}_{\mathrm{it}}
$$


where $\mathrm{a}_{\mathrm{it}}, \mathrm{c}_{\mathrm{it}}$ and $\mathrm{e}_{\mathrm{it}}$ are time specific effect, i.e., uncorrelated over time. The term $\mathrm{e}_{i t}$ includes measurement error. The score $\mathrm{y}^{*}$ it is decomposed into additive genetic (A), shared environmental (C), and unshared environmental (E) scores

$$
\mathrm{y}^{*}{ }_{\mathrm{it}}=\mathrm{A}_{\mathrm{it}}+\mathrm{C}_{\mathrm{it}}+\mathrm{E}_{\mathrm{it}}
$$

where $A_{i t}, C_{i t}$, and $E_{i t}$ are the zero mean additive genetic, shared environmental and unshared environmental scores at time $t$, respectively. Each latent source of individual differences is subject to the following longitudinal model (see Figure 1):

$$
\begin{aligned}
& \mathrm{A}_{\mathrm{it}}=\beta_{\text {At,t-1 }} \mathrm{A}_{\mathrm{it}-1}+\zeta_{\mathrm{Ait}} \\
& \mathrm{C}_{\mathrm{it}}=\beta_{\mathrm{Ct}, \mathrm{t}-1} \mathrm{C}_{\mathrm{it}-1}+\zeta_{\mathrm{Cit}} \\
& \mathrm{E}_{\mathrm{it}}=\beta_{\mathrm{Et}, \mathrm{t}-1} \mathrm{E}_{\mathrm{it}-1}+\zeta_{\mathrm{Eit}}
\end{aligned}
$$

Figure 1. The standard additive genetic, common (shared) and unshared environment (ACE) simplex model depicted for both twins, where $\mathrm{y}^{*}$ 's represent the series of observed phenotypes, A's represent the underlying additive genetic series, C's represent the underlying shared environment series, and E's represent the underlying unique environment series. Within each series, $\zeta$ represents innovation and $\beta$ represents stability. Conform biometric theory, the covariance between the A's at each time point is set equal to the $\operatorname{var}\left(\mathrm{A}_{\mathrm{t}}\right)$ (for $\mathrm{MZ}$ ) or $0.5 \operatorname{var}\left(\mathrm{A}_{\mathrm{t}}\right)$ (for $\mathrm{DZ}$ twins). For clarity reasons, time specific effects (i.e., a, c, and e) and phenotypic means are omitted. Note that the scaling and parameter labels are used throughout the series.

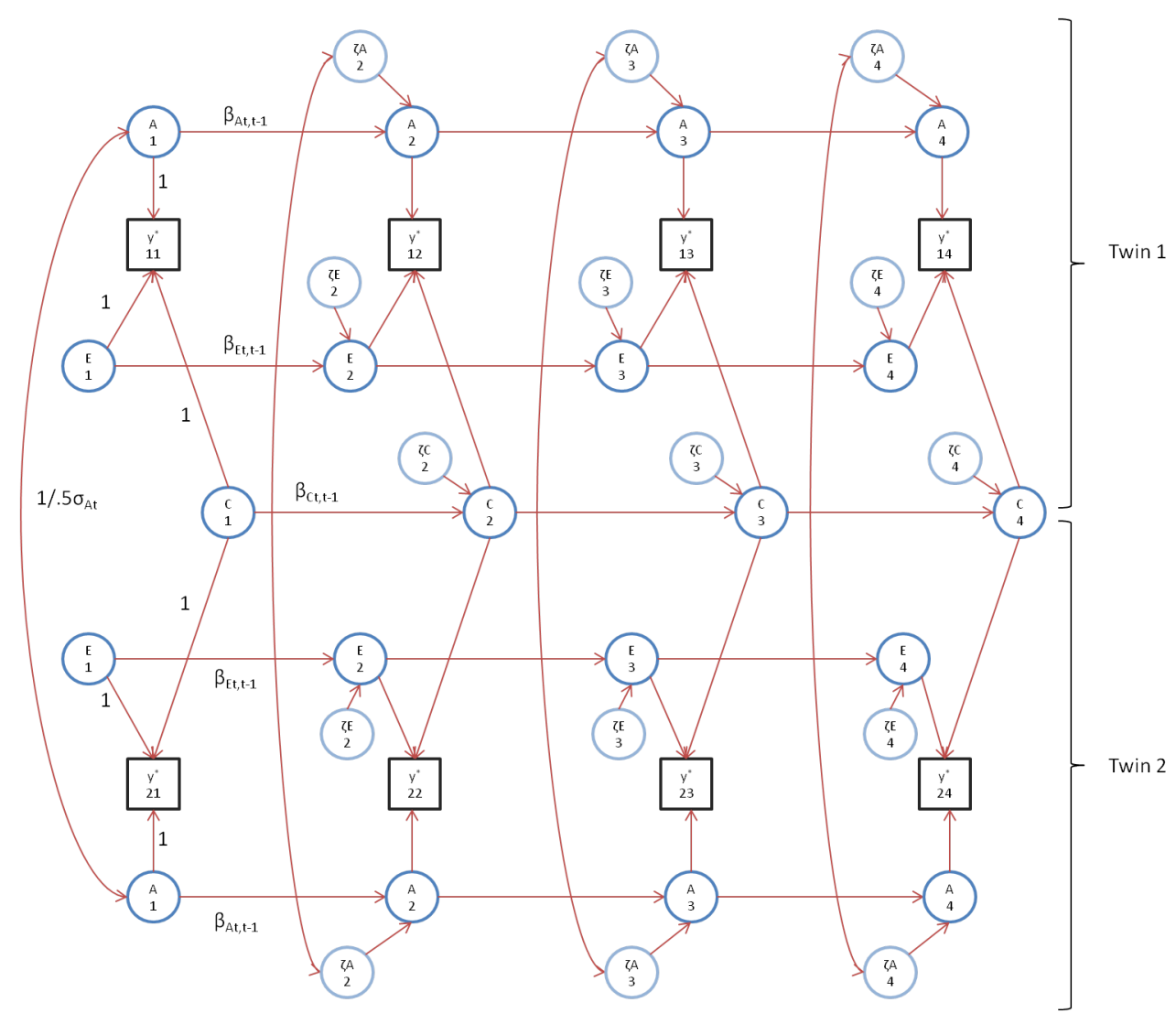


At $\mathrm{t}=1$, we set $\mathrm{A}_{\mathrm{i} 1}=\zeta_{\mathrm{Ai} 1}, \mathrm{C}_{\mathrm{i} 1}=\zeta_{\mathrm{Ci} 1}$, and $\mathrm{E}_{\mathrm{i} 1}=\zeta_{\mathrm{Ei} 1}$. Note that the latent variables $\mathrm{A}, \mathrm{C}$, and $\mathrm{E}$ at time $t$ are regressed on the variables at time $t-1$. The variables $\zeta_{\text {Ait }}, \zeta_{\text {Cit }}$, and $\zeta_{\text {Eit }}$ are uncorrelated with each other, but correlated over time (Equations (4)-(6)). As such, this model provides a decomposition into uncorrelated genetic and environmental components of phenotypic variance at each time point (Equation (2)), and of phenotypic stability (covariance) between time points (Equations (3)-(6)). The phenotypic stability is a function of the genotypic and environmental stabilities, which are quantified as explained variances of the latent regressions (Equations (4)-(6)). These depend both on the magnitude of the regression coefficients $\left(\beta_{\mathrm{At}, \mathrm{t}-1}, \beta_{\mathrm{Ct}, \mathrm{t}-1}, \beta_{\mathrm{Et}, \mathrm{t}-1}\right)$ and the (innovation) residual variances $\left(\operatorname{var}\left(\zeta_{\mathrm{Ait}}\right), \operatorname{var}\left(\zeta_{\mathrm{Cit}}\right), \operatorname{var}\left(\zeta_{\mathrm{Eit}}\right)\right)$.

The model is identified by constraining $\operatorname{cor}\left(\zeta_{\mathrm{A} 1 \mathrm{t}} \zeta_{\mathrm{A} 2 \mathrm{t}}\right)=\operatorname{cor}\left(\mathrm{a}_{1 \mathrm{t}} \mathrm{a}_{2 \mathrm{t}}\right)=0.5$ in DZ twins, and $\operatorname{cor}\left(\zeta_{\mathrm{A} 1 \mathrm{t}} \zeta_{\mathrm{A} 2 \mathrm{t}}\right)=\operatorname{cor}\left(\mathrm{a}_{1 \mathrm{t}} \mathrm{a}_{2 \mathrm{t}}\right)=1$ in MZ twins, and by constraining $\operatorname{cor}\left(\zeta_{\mathrm{C} 1 \mathrm{t}} \zeta_{\mathrm{C} 2 \mathrm{t}}\right)=\operatorname{cor}\left(\mathrm{c}_{1 \mathrm{t}} \mathrm{c}_{2 \mathrm{t}}\right)=1$ (note that $\operatorname{cor}\left(\zeta_{\mathrm{E} 1 \mathrm{t}} \zeta_{\mathrm{E} 2 \mathrm{t}}\right)=\operatorname{cor}\left(\mathrm{e}_{1 \mathrm{t}} \mathrm{e}_{2 \mathrm{t}}\right)=0$, by definition of these environmental influences being unshared). Note that at $\mathrm{t}=1$ and $\mathrm{t}=\mathrm{T}$, the time specific variances are not identified [16]. These variances are identified by imposing the over-identifying constraint that the variance components are equal over time (i.e., $\left.\operatorname{var}\left(\mathrm{a}_{\mathrm{t}}\right)=\operatorname{var}(\mathrm{a}), \operatorname{var}\left(\mathrm{c}_{\mathrm{t}}\right)=\operatorname{var}(\mathrm{c}), \operatorname{var}\left(\mathrm{e}_{\mathrm{t}}\right)=\operatorname{var}(\mathrm{e}), \mathrm{t}=1 \ldots 4\right)$.

The path diagram associated with this model is depicted in Figure 1. This model is quite flexible as it includes other models as special cases. For example, if the residual variance within a latent source of variance (e.g., $\left.\operatorname{var}\left(\zeta_{\text {Ait }}\right)(t=2, \ldots, T)\right)$ tends to zero in the presence of non-zero autoregression, this part of the model tends to a common factor model. We presented the ACE model here, as it counts as a standard model for repeated measures in GCSM of twin data and can therefore serve as a reference model. In the next section, we present our alternative $\mathrm{AE}^{*}$ model, which includes $\mathrm{Ph}-\mathrm{P}$ transmission.

\subsection{The AE* Simplex Model with Ph->E Transmission Applied to Twin Data}

The alternative model is depicted in Figure 2. Given zero $\mathrm{Ph}->\mathrm{E}$ transmission, the $\mathrm{AE}^{*}$ model is a special case of the standard ACE model. To transform the standard ACE model into alternative AE* model, we first discard the series of shared environmental effects $\left(C_{i t}\right)$. We introduce the environmental variables $\mathrm{E}^{*}{ }_{\text {it }}$, where we add an asterisk to emphasize that $\mathrm{E}^{*}$ it differs from the variable $\mathrm{E}_{\mathrm{it}}$ in the standard model. Within the alternative model, $\mathrm{E}^{*}$ it represents the total environmental influence, which is partially due to shared environmental factors (hence, the correlation between $\zeta_{\mathrm{E}^{*} 1 \mathrm{t}}$ and $\zeta_{\mathrm{E}^{*} \mathrm{t}}$ ), and partially due to unique environmental variance in $\zeta_{\mathrm{E}^{*} \text { it. }}$ The ACE model collapses into the $\mathrm{AE}^{*}$ model by imposing the constraint: $\beta_{\mathrm{Ct}, \mathrm{t}-1}=\beta_{\mathrm{Et}, \mathrm{t}-1}$ (i.e., the values of the autoregression series for the shared and unshared environmental series are set to be equal). As we explain below, we adopt this alternative treatment of environmental effects (E vs. $\left.E^{*}\right)$ for reasons of (empirical) identification.

As shown in Figure 2, the model also allows $\mathrm{Ph}-\mathrm{E}$ transmission, via regression of the environmental variables at $t, E^{*}{ }_{1 t}$ and $E^{*}{ }_{2 t}$ on the twins' phenotypes at the preceding time $y_{1 t-1}$ and $y_{2 t-1}$ (the relevant parameters are denoted $\alpha_{\mathrm{t}}$ and $\gamma_{\mathrm{t}}$ ). As above, the phenotype at each time point is related to the intercept $\beta_{0 \mathrm{t}}$ (the phenotypic mean at time $\mathrm{t}$ ) the time specific residual $\left(\mathrm{z}_{\mathrm{it}}\right)$, and the zero mean additive genetic $\left(\mathrm{A}_{\mathrm{it}}\right)$ and environmental variables $\left(\mathrm{E}^{*}{ }_{\mathrm{it}}\right)$ :

$$
\begin{gathered}
y_{i t}=\beta_{0 t}+y_{i t}^{*}+z_{i t} \\
y_{i t}^{*}=A_{i t}+E^{*}{ }_{i t}
\end{gathered}
$$


Also, the additive genetic variables are subject to the first order autoregression:

$$
\mathrm{A}_{\mathrm{it}}=\beta_{\mathrm{At}, \mathrm{t}-1} \mathrm{~A}_{\mathrm{it}-1}+\zeta_{\mathrm{Ait}}
$$

However, the environmental variables in twin members 1 and 2 are not only regressed on the preceding environmental variables but also on the preceding phenotypes:

$$
\begin{aligned}
& \mathrm{E}^{*}{ }_{1 \mathrm{t}}=\beta_{\mathrm{Et}, \mathrm{t}-1} \mathrm{E}^{*}{ }_{1 \mathrm{t}-1}+\alpha_{\mathrm{t}} \mathrm{y}^{*}{ }_{1 \mathrm{t}-1}+\gamma_{\mathrm{t}} \mathrm{y}^{*}{ }_{2 \mathrm{t}-1}+\zeta_{\mathrm{E}^{*} 1 \mathrm{t}} \\
& \mathrm{E}^{*}{ }_{2 \mathrm{t}}=\beta_{\mathrm{Et}, \mathrm{t}-1} \mathrm{E}^{*}{ }_{2 \mathrm{t}-1}+\gamma_{\mathrm{t}} \mathrm{y}^{*}{ }_{1 \mathrm{t}-1}+\alpha_{\mathrm{t}} \mathrm{y}^{*}{ }_{2 \mathrm{t}-1}+\zeta_{\mathrm{E}^{*} 2 \mathrm{t}},
\end{aligned}
$$

where the $\mathrm{Ph}->\mathrm{E}$ transmission parameters are $\alpha_{\mathrm{t}}$ (transmission within a twin member, e.g., $\alpha_{t} \mathrm{y}^{*}{ }_{1 \mathrm{t}-1}$ ) and $\gamma_{\mathrm{t}}$ (transmission across twin members, e.g., $\gamma_{\mathrm{t}} \mathrm{y}^{*}{ }_{2 \mathrm{t}-1}$ ). Again at $\mathrm{t}=1$, we set $\mathrm{A}_{\mathrm{i} 1}=\zeta_{\mathrm{Ail}}$ and $\mathrm{E}^{*}{ }_{\mathrm{i} 1}=\zeta_{\mathrm{E}^{*} \mathrm{i} 1}$. By including the $\alpha_{t}$ parameter, we recognize that the phenotype of each twin member may contribute directly to his or her own environment (i.e., niche picking, [4,5]). By including the $\gamma_{\mathrm{t}}$ parameter, we recognize that the phenotype of one twin member may also contribute to the environment of the other twin member (i.e., sibling effects) $[14,17,18]$. Both niche picking and sibling effects are concepts which match the phenotype to the environment, which plays an important role in D\&F model [1]. By substituting $\mathrm{y}^{*}{ }_{\text {it }}$ in Equations (10a) and (11a) for $\mathrm{y}^{*}{ }_{\mathrm{it}}$ given in Equations (8), we have:

$$
\begin{aligned}
& E_{1 t}^{*}=\beta_{E t, t-1} E^{*}{ }_{1 t-1}+\alpha_{t}\left(A_{1 t-1}+E^{*}{ }_{1 t-1}\right)+\gamma_{t}\left(A_{2 t-1}+E^{*}{ }_{2 t-1}\right)+\zeta_{E^{*} 1 t} \\
& E^{*}{ }_{2 t}=\beta_{E t, t-1} E^{*}{ }_{2 t-1}+\gamma_{t}\left(A_{1 t-1}+E^{*}{ }_{1 t-1}\right)+\alpha_{t}\left(A_{2 t-1}+E^{*}{ }_{2 t-1}\right)+\zeta_{E^{*} 2 t}
\end{aligned}
$$

Given to this substitution, it is clear that a part of the environment is under genetic control. This genetic control, due to matching, is expressed in the terms $\alpha_{t}\left(A_{i t-1}\right)$ and $\gamma_{t}\left(A_{i t-1}\right)$. Additionally, when writing out the equation for consecutive time points, it will become evident that due to the interplay between the phenotype and environment, a higher IQ leads to a better environment, which, in turn, leads to a higher IQ. This interplay thus functions as the multiplier.

Note that the rational to introduce $\mathrm{Ph}->\mathrm{E}$ transmission in the alternative AE model and not in the ACE model is based on statistical considerations. De Kort et al. and Dolan et al. studied the issues of parameter identification and power when allowing $\mathrm{Ph}->\mathrm{E}$ transmission in both the ACE model and the $\mathrm{AE}^{*}[19,20]$. They showed that the resolution of the $\mathrm{Ph}->\mathrm{E}$ transmission parameters $\left(\alpha_{\mathrm{t}}\right.$ and $\left.\gamma_{\mathrm{t}}\right)$ is extremely poor in the presence of an independent $\mathrm{C}$ simplex (i.e., Equation (5)). This is because $\mathrm{Ph}-\mathrm{E}$ transmission itself gives rise to correlated environmental variables (see below; Tables 4 and 5). Within the $\mathrm{AE}^{*}$ model, the resolution of the $\mathrm{Ph}-\mathrm{E}$ transmission parameters improves considerably. In presence of $\mathrm{Ph}->\mathrm{E}$ transmission, the correlations between $\zeta_{\mathrm{E} * 1 \mathrm{t}}$ and $\zeta_{\mathrm{E} * 2 \mathrm{t}}$ are due to shared environmental influences in addition to the correlated environment originating in the $\mathrm{Ph}->\mathrm{E}$ transmission [19]. Dolan et al. established that, given four time points, the parameters $\alpha_{t}$ and $\gamma_{t}$ are identified subject to equality constraints (e.g., $\alpha_{2}=\alpha_{3}$ and $\gamma_{2}=\gamma_{3}$ ) [20]. Here, we impose the over-identifying constraint $\alpha_{\mathrm{t}}=\alpha_{\mathrm{t}-1}$ and $\gamma_{\mathrm{t}}=\gamma_{\mathrm{t}-1}, \mathrm{t}=2,3,4$, and therefore drop the time subscript (i.e., the parameters are denoted $\alpha$ and $\gamma)$. As above, remaining identification issues are resolved by $\operatorname{cor}\left(\zeta_{\mathrm{A} 1 \mathrm{t}} \zeta_{\mathrm{A} 2 \mathrm{t}}\right)=\operatorname{cor}\left(\mathrm{a}_{1 \mathrm{t}} \mathrm{a}_{2 \mathrm{t}}\right)=0.5$ in DZ twins, $\operatorname{cor}\left(\zeta_{\mathrm{A} 1 \mathrm{t}} \zeta_{\mathrm{A} 2 \mathrm{t}}\right)=\operatorname{cor}\left(\mathrm{a}_{1 \mathrm{t}} \mathrm{a}_{2 \mathrm{t}}\right)=1$ in MZ twins, and $\operatorname{cor}\left(\mathrm{c}_{1 \mathrm{t}} \mathrm{c}_{2 \mathrm{t}}\right)=1$. As depicted in Figure 2 and discussed above, at $t=1$, we assume that GE-cov is zero. This is a strong assumption, to which we return below. 
Figure 2. The $\mathrm{AE}^{*}$ simplex model with $\mathrm{Ph}->\mathrm{E}$ transmission, where parameters $\alpha$ can be interpreted as within twin $\mathrm{Ph}->\mathrm{E}$ transmission and $\gamma$ as between twin $\mathrm{Ph}->\mathrm{E}$ transmission, and where y's are the series of observed variables, A's are the underlying additive genetic series, E's are the underlying unique environment series and $*$ denotes the time point specific environmental covariance (indicative of $\mathrm{C}$ ). Conform biometric theory, the covariance between the A's at each time point is set equal to the $\operatorname{var}\left(A_{t}\right)$ (for $M Z$ ) or $0.5 \operatorname{var}\left(\mathrm{A}_{t}\right)$ (for $\mathrm{DZ}$ twins). For clarity reasons, time specific effects and phenotypic means are omitted. Note that the scaling and parameter labels are used throughout the series.

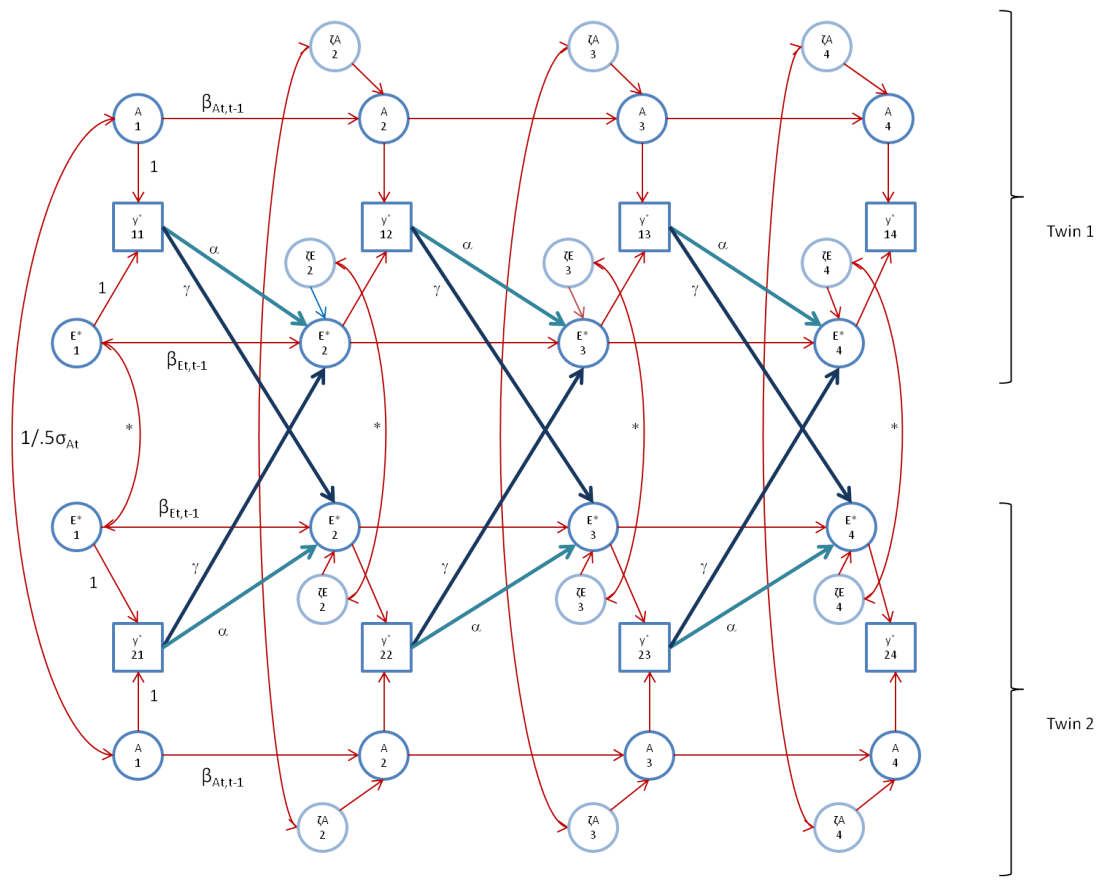

\section{Method}

We applied the ACE simplex and the $\mathrm{AE}^{*}$ simplex with $\mathrm{Ph}->\mathrm{E}$ transmission to full scale IQ (i.e., FSIQ) and performance IQ (i.e., perfIQ). The data are obtained from the Netherlands Twin Register (NTR) [21,22], which includes the Young NTR (YNTR) [23]. This register has collected IQ test score using different instruments at consecutive population-based surveys in the Netherlands. The twins were measured at mean (SD) ages of 5.5 years $(0.30), 6.8$ years $(0.19), 9.7$ years $(0.43)$, and 12.2 years (0.24) and were born between 1984 and 1996. The IQ scores were obtained using the Revised Amsterdam Children Intelligence Test (RAKIT) [24] at ages 5.5 years, 6.8 years, 9.7 years, and two Dutch versions of the Wechsler Intelligence Scale for Children (WISC-R and WISC-R III) [25,26] at age 9.7 years and 12.2 years. Of the RAKIT, three sub-tests were used to measure performance IQ (exclusion, discs, and hidden figures) and three sub-tests were used to measure verbal IQ (learning names, verbal meaning, and idea production). Of the WISC, either all 12 sub-tests were used to measure performance and verbal IQ, or two sub-tests were used to measure performance IQ (block design, and object assembly) and four sub-tests were used to measure verbal IQ (similarities, vocabulary, arithmetic, digit span). The test scores were subjected to age appropriate scaling, and standardized following the guidelines in the tests' manuals [24-26]. For each age, the combination of nonverbal and verbal IQ was used as a measure of full scale IQ. Note that the use of different tests is due to the 
different surveys in which the data was gathered and age of the participants. Standardized IQ scores based on the subset of WISC-R scales correlate 0.94 with standardized IQ scores based on all subtests of the WISC-R [27,28]. Additionally, the concurrent validity between the RAKIT and the WISC-R is $0.86[29]$.

The total sample size varied as a function of missingness. The FSIQ data comprised $261 \mathrm{MZ}$ and $301 \mathrm{DZ}$ twin pairs. The proportions of observed FSIQ data at $\mathrm{t}=1, \ldots, 4$ are $0.812,0.295,0.490,0.828$ (MZ twin 1 and $\mathrm{MZ}$ twin 2), 0.774, 0.379, 0.598, 0.797 (DZ twin 1 and DZ twin 2). The perfIQ data comprised $291 \mathrm{MZ}$ and $337 \mathrm{DZ}$ twin pairs. The proportions of observed perfIQ data at $\mathrm{t}=1, \ldots, 4$ are 0.376, 0.333, 0.551, 0.927 (MZ twin 1 and MZ twin 2), 0.438, 0.432, 0.682, 0.909 (DZ twin1 and DZ twin 2).

Given the missingness, the models were fitted using full information maximum likelihood (FIML) estimation in the Mplus 6.11 program [30], assuming multivariate normality (Mplus input files are available from JMdeK, the corresponding author). We evaluated model fit in terms of the $\chi^{2}$ goodness of fit index, incremental fit index TLI ( $>0.95$ acceptable, $>0.97$ good), the BIC and the sample size adjusted Bayesian Information criterion (adjBIC; the smaller the better), and the RMSEA, with 95\% confidence intervals ( $<0.08$ acceptable; $<0.05$ good). The criteria given in parentheses are based on Schermelleh-Engel, Moosbrugger, and Müller [31]. The FIML estimates of the means, standard deviations, and correlation matrices are given in the appendix. We tested for sex differences in both FSIQ and perfIQ. At none of the time points, sex differences were found to be significant (given $\alpha=0.05 / 4$ ). As such, we excluded sex from the analyses.

Note that our main objective is to introduce a model that can aid in understanding the Flynn effect. We do not analyze the data thoroughly, but we merely use the data for illustrative purposes. Therefore, we assume that the pattern of missingness does not pose a problem in our analyses as the effect of non-sampling on the means is usually much greater than the effect on the covariance structure. Within our analyses, we focus on the latter. The first analysis in which we fit the standard ACE model merely serves as a reference to evaluate the credibility of our extended AE* model, and the second analysis merely serves as a tool to find credible parameter estimates. Results presented here should be interpreted in this light.

\section{Results}

\subsection{Standard Model: ACE Simplex}

We first fitted the standard genetic simplex model, as depicted in Figure 1 (note that, to avoid clutter, Figure 1 does not include occasion specific effects). As mentioned above, we constrained the occasion specific genetic and environmental variances to be equal over time $\left(\operatorname{var}\left(\mathrm{a}_{\mathrm{t}}\right)=\operatorname{var}(\mathrm{a})\right.$, $\left.\operatorname{var}\left(c_{t}\right)=\operatorname{var}(c), \operatorname{var}\left(e_{t}\right)=\operatorname{var}(e), t=1, \ldots, 4\right)$. For FSIQ, the standard simplex model fitted the data well $\left(\chi^{2}(60)=76.8 ; \mathrm{TLI}=0.99 ; \operatorname{adjBIC}=21,470 ; \mathrm{BIC}=21,559 ; \mathrm{RMSEA}=0.032(\mathrm{CI95}: 0.0-0.051)\right)$. The time-specific genetic variance (denoted $\operatorname{var}(\mathrm{a})$ above) (1 parameter) and the variances $\operatorname{var}\left(\zeta_{\mathrm{A} 3}\right)$ and $\operatorname{var}\left(\zeta_{\mathrm{A} 4}\right)$ (two parameters) were estimated at zero. They were therefore fixed to zero, and the model refitted: $\chi^{2}(63)=76.8$; TLI $=0.99$; adjBIC $=21,460 ; \mathrm{BIC}=21,540 ;$ RMSEA $=0.028$ (CI95: 0.0-0.048). The fact that the $\chi^{2}$ is unchanged is consistent with the fact that the fixed variances were estimated as zero. Although some parameters were not significant (at $\alpha=0.01$, say) in this model, we made no 
effort to further prune the model. In the analysis of perfIQ, we obtained similar results. The standard simplex model fitted the data well $\left(\chi^{2}(60)=56.9\right.$; TLI $>0.99$; adjBIC $=18,496$; $\mathrm{BIC}=18,585$; RMSEA $=0.0$ (CI95: 0.0-0.035)). The time-specific genetic variance was zero (one parameter), as were $\operatorname{var}\left(\zeta_{\mathrm{A} 2}\right), \operatorname{var}\left(\zeta_{\mathrm{A} 3}\right)$ (two parameters), and $\operatorname{var}\left(\zeta_{\mathrm{C} 2}\right), \operatorname{var}\left(\zeta_{\mathrm{C} 3}\right), \operatorname{var}\left(\zeta_{\mathrm{C} 4}\right)$, and $\operatorname{var}\left(\zeta_{\mathrm{E} 3}\right)$ (four parameters). We refitted the model with these parameters fixed to zero, and obtained $\chi^{2}(67)=56.9$, $\mathrm{TLI}>0.99$, adjBIC $=18,475, \mathrm{BIC}=18,541$, and RMSEA $=0.0($ CI95: 0.0-0.025).

Based on the parameter estimates, we calculated genetic and environmental covariance matrices, and the standardized variance components (Table 1). These results are quite consistent with the literature [32-36]. For instance, the relative contribution of additive genetic influences to the phenotypic (co-) variance increases (FSIQ: 0.27-0.54; perfIQ: 0.29-0.53), and that of shared environmental influences decreases (FSIQ: $0.50-0.24$ perfIQ: 0.36-0.18). Genetic influences are highly stable (genetic correlations 0.801-1) in contrast to unshared environmental influences (correlations 0.002-0.205). We note that the results obtained with FSIQ and perfIQ are quite similar.

Table 1. Standard ACE simplex model results of full scale IQ (FISQ) and performance IQ (perfIQ): Correlations among A, E, and C, standard deviations, variances and standardized variance. Note in this model $\mathrm{A}, \mathrm{C}$, and $\mathrm{E}$ are uncorrelated.

\begin{tabular}{|c|c|c|c|c|c|c|c|c|}
\hline \multirow[b]{2}{*}{ Age in years: } & \multicolumn{4}{|c|}{ FSIQ } & \multicolumn{4}{|c|}{ perfIQ } \\
\hline & 5.5 & 6.8 & 9.7 & 12.2 & 5.5 & 6.8 & 9.7 & 12.2 \\
\hline & \multicolumn{4}{|c|}{$\mathbf{A}$} & \multicolumn{4}{|c|}{$\mathbf{A}$} \\
\hline \multirow{4}{*}{ Correlations } & 1.000 & & & & 1.000 & & & \\
\hline & 0.801 & 1.000 & & & 1.000 & 1.000 & & \\
\hline & 0.801 & 1.000 & 1.000 & & 1.000 & 1.000 & 1.000 & \\
\hline & 0.801 & 1.000 & 1.000 & 1.000 & 0.959 & 0.959 & 0.959 & 1.000 \\
\hline Standard deviation & 7.69 & 10.21 & 11.84 & 10.52 & 7.58 & 11.67 & 12.38 & 12.37 \\
\hline Variance & 59.1 & 104.3 & 140.1 & 110.8 & 57.4 & 136.2 & 153.3 & 152.9 \\
\hline \multirow[t]{2}{*}{$\begin{array}{c}\text { Standardized } \\
\text { variance } \\
\end{array}$} & 0.27 & 0.48 & 0.60 & 0.54 & 0.29 & 0.50 & 0.60 & 0.53 \\
\hline & \multicolumn{4}{|c|}{$\mathbf{E}$} & \multicolumn{4}{|c|}{$\mathbf{E}$} \\
\hline \multirow{4}{*}{ Correlations } & 1.000 & & & & 1.000 & & & \\
\hline & 0.112 & 1.000 & & & 0.077 & 1.000 & & \\
\hline & 0.056 & 0.212 & 1.000 & & 0.048 & 0.205 & 1.000 & \\
\hline & 0.030 & 0.115 & 0.119 & 1.000 & 0.002 & 0.008 & 0.005 & 1.000 \\
\hline Standard deviation & 7.02 & 7.93 & 6.80 & 6.78 & 8.35 & 9.41 & 8.28 & 9.18 \\
\hline Variance & 49.3 & 62.9 & 46.2 & 46.0 & 69.6 & 88.5 & 68.5 & 84.2 \\
\hline \multirow[t]{2}{*}{ Standardized variance } & 0.23 & 0.29 & 0.20 & 0.22 & 0.35 & 0.32 & 0.27 & 0.29 \\
\hline & \multicolumn{4}{|c|}{$\mathrm{C}$} & \multicolumn{4}{|c|}{$\mathbf{C}$} \\
\hline \multirow{4}{*}{ Correlations } & 1.000 & & & & 1.000 & & & \\
\hline & 0.756 & 1.000 & & & 0.760 & 1.000 & & \\
\hline & 0.457 & 0.478 & 1.000 & & 0.697 & 0.658 & 1.000 & \\
\hline & 0.400 & 0.418 & 0.675 & 1.000 & 0.768 & 0.724 & 0.665 & 1.000 \\
\hline Standard deviation & 10.39 & 7.08 & 6.78 & 7.05 & 8.39 & 6.96 & 5.88 & 7.16 \\
\hline Variance & 107.8 & 50.1 & 46.0 & 49.8 & 70.5 & 48.5 & 34.6 & 51.3 \\
\hline Standardized variance & 0.50 & 0.23 & 0.20 & 0.24 & 0.36 & 0.18 & 0.14 & 0.18 \\
\hline
\end{tabular}




\subsection{Alternative Model: AE* Simplex with Ph->E Transmission}

We fitted the alternative model, the $\mathrm{AE}^{*}$ simplex model with $\mathrm{Ph}->\mathrm{E}$ transmission, as depicted in Figure 2 (Figure 2 does not display the occasion specific effects). As above, we constrained the occasion specific genetic and environmental variances to be equal over time. The alternative simplex model fitted the FSIQ data well $\left(\chi^{2}(61)=73.3\right.$; TLI $>0.99$; adjBIC $=21,463 ; \mathrm{BIC}=21,549$; RMSEA $=0.027$ (CI95: $0.0-0.047)$ ). However, in this model, some variances were estimated at zero. We reduced the model in the following way. First, as in the standard model, the variance $\operatorname{var}(\mathrm{a})$, and the variances $\operatorname{var}\left(\zeta_{\mathrm{A} 3}\right)$ and $\operatorname{var}\left(\zeta_{\mathrm{A} 4}\right)$ were estimated at zero, so we fixed these to zero, (three parameters). In addition, the unshared environmental auto-regression coefficients $\left(\beta_{\mathrm{Et}, \mathrm{t}-1}\right)$ were near (one time) zero or (two times) negative (i.e., hard to interpret), and none were significant, so we fixed these to zero (three parameters). Finally, the correlations between $\zeta_{\mathrm{E}^{*} 1 \mathrm{t}}$ and $\zeta_{\mathrm{E}^{*} 2 \mathrm{t}}$ at $\mathrm{t}=2,3,4$ were not significant, so we fixed these to zero (three parameters). The goodness of fit indices of the resulting model are $\chi^{2}(70)=74.9$, LI $>0.99$, $\operatorname{adjBIC}=21,463, \mathrm{BIC}=21,494$, and RMSEA $=0.016(\mathrm{CI95}: 0.0-0.039)$. The small increase in $\left.\chi^{2}(9)=1.6\right)$ underlines the non-significance of the dropped parameters. The genetic autoregressive coefficients equaled 0.761 (s.e. 0.276), 1.062 (s.e. 0.133), and 0.772 (s.e. 0.124). We constrained these to be equal merely to facilitate subsequent calculations (see below). This resulted in $\chi^{2}(72)=77.379$, TLI $>0.99$, $\operatorname{adjBIC}=21,432, \mathrm{BIC}=21,483$, and $\mathrm{RMSEA}=0.016$ (CI95: 0-0.039), and a test for the equality constraints of $\chi^{2}(2)=2.48(p=0.29)$, which suggests that the equality constraint is tenable. Table 2 contains the parameter estimates of this model, Table 3 contains the standardized variance components, and Table 4 contains the covariance matrices of $\mathrm{A}$ and $\mathrm{E}^{*}$, based on the estimates in Table 2. Figure 3 shows the model as fitted. This final model gives rise to an $\mathrm{AE}^{*}$ correlation equaling $0(\mathrm{t}=1), 0.32(\mathrm{t}=2), 0.56$ $(\mathrm{t}=3)$ and $0.66(\mathrm{t}=4)$. As formulated, at time point 1 , we assume GE-cov $=0$. However, within the final model, the within twin member correlation between $A_{i 1}$ and $E^{*}{ }_{i 1}$ is identified. To evaluate whether our initial assumption is correct, we refitted the model to estimate $\operatorname{cor}\left(\mathrm{A}_{1}, \mathrm{E}^{*}{ }_{1}\right)$. Based on the Wald test, this parameter showed not to be significant $\left(\operatorname{cor}\left(\mathrm{A}_{1}, \mathrm{E}^{*}{ }_{1}\right)=-0.018\right.$, s.e. 0.032$)$.

Table 2. FIML parameters and standard errors (s.e.) of the $\mathrm{AE}^{*}$ model with $\mathrm{Ph}-\mathrm{E}$ transmission as fitted to FSIQ and perfIQ. $0 *$ indicates that the parameter value was fixed to zero.

\begin{tabular}{ccc}
\hline Parameter & FSIQ ML Estimate (s.e.) & perfIQ ML Estimate (s.e.) \\
\hline$\alpha_{1}=\alpha_{2}=\alpha_{3}$ & $0.385(0.13)$ & $0.482(0.147)$ \\
$\gamma_{1}=\gamma_{2}=\gamma_{3}$ & $0.070(0.03)$ & $0.037(0.028)$ \\
$\operatorname{var}\left(\zeta_{\mathrm{E}^{*} 1}\right)^{0.5}=\operatorname{var}\left(\mathrm{E}_{1}\right)^{0.5}$ & $10.18(0.74)$ & $5.68(1.301)$ \\
$\operatorname{var}\left(\zeta_{\mathrm{E}^{*} 2}\right)^{0.5}$ & $5.644(1.39)$ & $5.46(1.010)$ \\
$\operatorname{var}\left(\zeta_{\mathrm{E}^{*} 3}\right)^{0.5}$ & $4.197(2.00)$ & $0^{*}$ \\
$\operatorname{var}\left(\zeta_{\mathrm{E}^{*} 4}\right)^{0.5}$ & $3.857(2.00)$ & $4.819(0.974)$ \\
$\operatorname{cor}\left(\mathrm{E}^{*}{ }_{11} \mathrm{E}^{*}{ }_{21}\right)$ & $0.804(0.12)$ & $0.765(0.249)$ \\
$\operatorname{var}\left(\zeta_{\mathrm{A} 1}\right)^{0.5}=\operatorname{var}\left(\mathrm{A}_{1}\right)^{0.5}$ & $7.964(0.80)$ & $9.041(0.813)$ \\
$\operatorname{var}\left(\zeta_{\mathrm{A} 2}\right)^{0.5}$ & $4.185(1.10)$ & $0 *$ \\
$\operatorname{var}\left(\zeta_{\mathrm{A} 3}\right)^{0.5}$ & $0 *$ & $0 *$ \\
$\operatorname{var}\left(\zeta_{\mathrm{A}}\right)^{0.5}$ & $0^{*}$ & $4.482(1.471)$ \\
$\beta_{\mathrm{Att}, \mathrm{t}-1(\mathrm{t}=2,3,4)}$ & $0.895(0.06)$ & $0.877(0.095)$ \\
$\operatorname{var}(\mathrm{e})^{0.5}$ & $5.350(1.32)$ & $7.763(0.340)$ \\
$\operatorname{var}(\mathrm{c})^{0.5}$ & $4.277(0.35)$ & $3.620(0.620)$ \\
\hline
\end{tabular}


Table 3. Decomposition of phenotypic variance into $\mathrm{A}, \mathrm{E}^{*}, \mathrm{AE}^{*}$-cov and $\mathrm{C}$ components. The standardized components are given in parentheses. Note that here $\operatorname{var}\left(\mathrm{E}^{*}\right)$ includes both $\operatorname{var}\left(\zeta_{\mathrm{E}}\right)$ and $\operatorname{var}(\mathrm{e})$ and $\mathrm{C}$ is limited to time specific effects $(\operatorname{var}(\mathrm{c}))$. Additive genetic time specific effects are absent.

\begin{tabular}{|c|c|c|c|c|c|c|}
\hline Age & $\operatorname{var(FSIQ)~}$ & $\operatorname{var}(\mathrm{A})$ & $\operatorname{var}\left(E^{*}\right)$ & $\operatorname{var}(C)$ (Time Specific) & $2 \operatorname{cov}\left(\mathrm{AE}^{*}\right)$ & $2 \operatorname{cov}\left(A E^{*}\right)+\operatorname{var}(A)$ \\
\hline 5.5 years & 214.1 & $63.43(0.30)$ & $132.40(0.62)$ & $18.29(0.09)$ & $0(0)$ & $63.43(0.30)$ \\
\hline 6.8 years & 226.5 & $68.3(0.30)$ & $92.29(0.41)$ & $18.29(0.08)$ & $47.6(0.21)$ & $115.9(0.51)$ \\
\hline 7.9 years & 221.3 & $54.7(0.25)$ & $78.63(0.36)$ & $18.29(0.08)$ & $69.6(0.31)$ & $124.3(0.56)$ \\
\hline 12.2 years & 205.5 & $43.8(0.21)$ & $75.39(0.37)$ & $18.29(0.09)$ & $67.8(0.33)$ & $111.6(0.54)$ \\
\hline Age & $\operatorname{var}($ perfIQ) & $\operatorname{var}(\mathbf{A})$ & $\operatorname{var}\left(E^{*}\right)$ & $\operatorname{var}(C)$ (Time Specific) & $2 \operatorname{cov}\left(A E^{*}\right)$ & $2 \operatorname{cov}\left(A E^{*}\right)+\operatorname{var}(A)$ \\
\hline 5.5 years & 187.4 & $81.7(0.44)$ & $92.6(0.49)$ & $13.1(0.07)$ & $0(0)$ & $81.7(0.44)$ \\
\hline 6.8 years & 266.8 & $62.8(0.24)$ & $119.1(0.45)$ & $13.1(0.05)$ & $71.7(0.27)$ & $134.5(0.51)$ \\
\hline 7.9 years & 256.9 & $48.3(0.19)$ & $108.7(0.42)$ & $13.1(0.05)$ & $86.8(0.34)$ & $135.1(0.53)$ \\
\hline 12.2 years & 281.1 & $57.3(0.20)$ & $130.0(0.46)$ & $13.1(0.05)$ & $80.7(0.29)$ & $138.0(0.49)$ \\
\hline
\end{tabular}

In the analysis of perfIQ, we fitted the model with the time-specific genetic variances (one parameter), and $\operatorname{var}\left(\zeta_{\mathrm{A} 2}\right), \operatorname{var}\left(\zeta_{\mathrm{A} 3}\right)$ (two parameters), and the correlations between $\zeta_{\mathrm{E}^{*} 1 \mathrm{t}}$ and $\zeta_{\mathrm{E}^{*} 2 \mathrm{t}}$ at $\mathrm{t}=2,3,4$ fixed to zero. The model fitted well $\left(\chi^{2}(67)=59.7\right.$; TLI $>0.99 ;$ adjBIC $=18,477$; $\mathrm{BIC}=18,544 ; \mathrm{RMSEA}=0.0(\mathrm{CI} 95: 0.0-0.029))$. However, as in FSIQ, the unshared environmental auto-regression coefficients $\left(\beta_{\mathrm{E}, \mathrm{t}-\mathrm{1}-1}\right)$ were not significant, and $\operatorname{var}\left(\zeta_{\mathrm{E} 3}\right)$ was zero. We dropped these parameters to arrive at $\chi^{2}(71)=60.43$, TLI $>0.99$, adjBIC $=18,466, \mathrm{BIC}=18,520$, and $\mathrm{RMSEA}=0.0$ (CI95: 0.0-0.024). The genetic autoregressive coefficients equaled 0.791 (s.e. 0.189), 0.787 (s.e. 0.194), and 0.977 (s.e. 0.178). As above, we constrained these to be equal to facilitate subsequent calculations (see below). This resulted in $\chi^{2}(73)=61.1$, TLI $>0.99$, adjBIC $=18,460$, $\mathrm{BIC}=18,508$, and RMSEA $=0.0$ (CI95: 0-0.022), and a test for the equality constraints of $\chi^{2}(2)=0.75(p=0.69)$. The results are given in Table 2, 3, and 5. Figure 4 depicts the model as fitted. This final model gives rise to an $\mathrm{AE}^{*}$ correlation equaling $0(\mathrm{t}=1), 0.41(\mathrm{t}=2), 0.60(\mathrm{t}=3)$ and 0.47 $(t=4)$. We estimated $\operatorname{cor}\left(A_{1}, E^{*} 1\right)$, and found this correlation to be zero $\left(\operatorname{cor}\left(A_{1}, E^{*}\right)=-0.002\right.$, s.e. 0.078$)$. 
Figure 3. The $\mathrm{AE}^{*}$ simplex model with $\mathrm{Ph}->\mathrm{E}$ transmission as fitted to FSIQ. Time specific effects are not shown. Note that in FSIQ, time specific effects were found to be environmental (time specific genetic variance was zero).

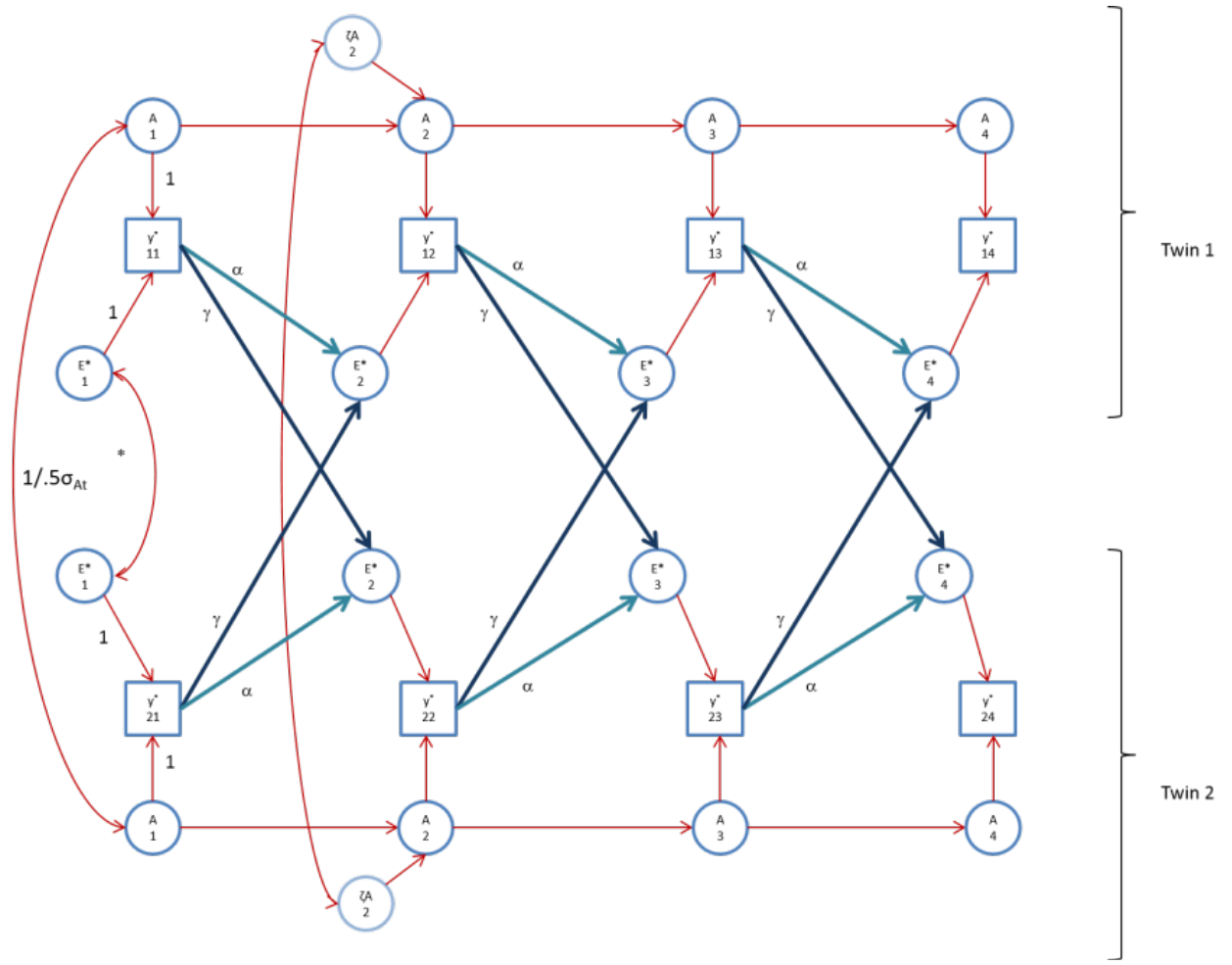

Figure 4. The $\mathrm{AE}^{*}$ simplex model with $\mathrm{Ph}->\mathrm{E}$ transmission as fitted to perfIQ. Time specific effects are not shown. Note that in perfIQ, time specific effects were found to be environmental (time specific genetic variance was zero).

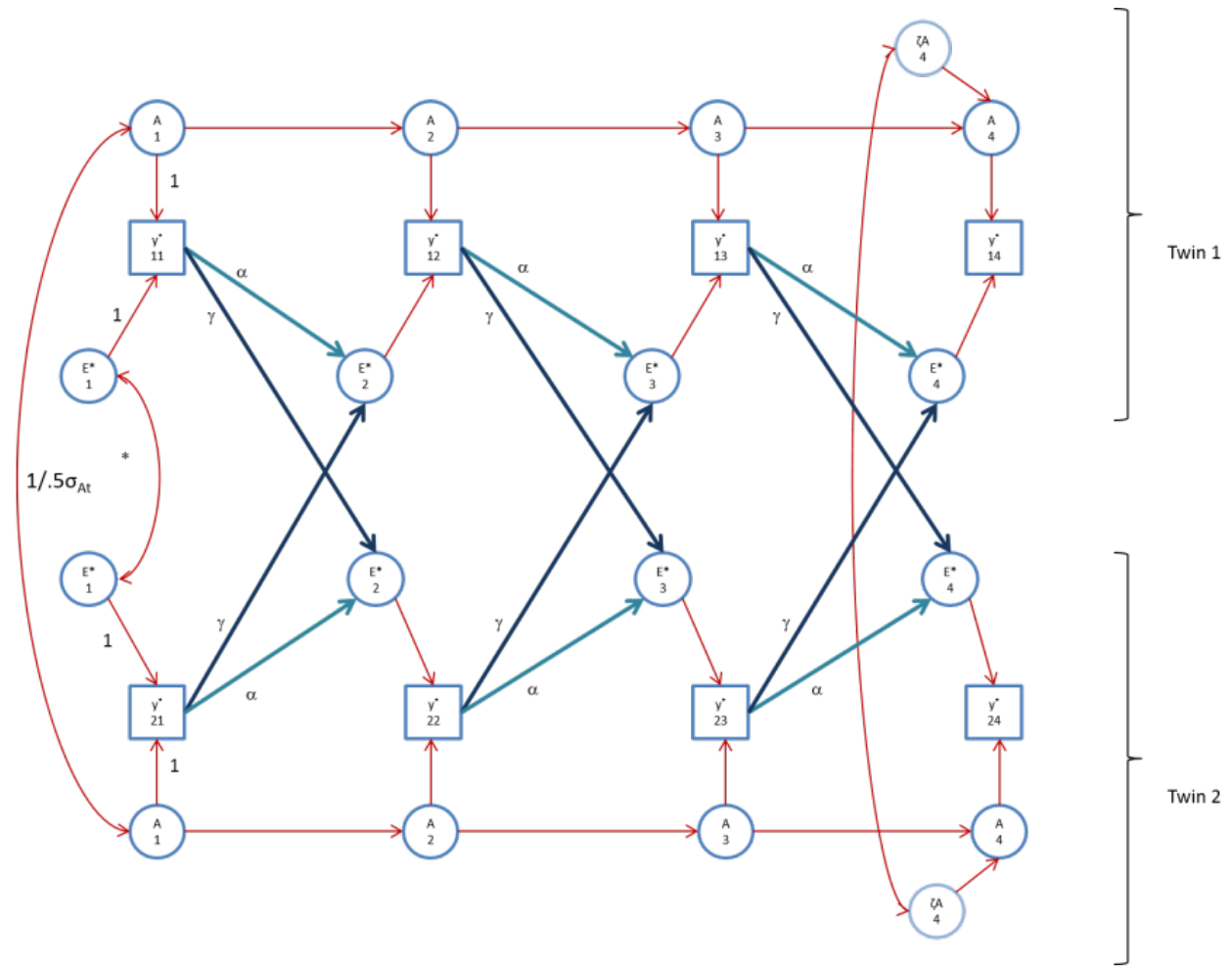


The standard ACE simplex model and the AE* simplex with $\mathrm{Ph}-\mathrm{PE}$ transmission both fitted well judging by the fit indices. The information criteria BIC and adjBIC favored the alternative model, although the differences are not large, and the models are not nested (FSIQ: adjBIC: 21,460 vs. 21,432 and 21,540 vs. 21,483; perfIQ: 18,475 vs. 18,460 and 18,541 vs. 18,508). Based on the similarity between the fit indices, we conclude that the extended $\mathrm{AE}^{*}$ model fits the data adequately relative to the standard ACE model, and therefore is compatible with the standard ACE model.

Comparison of the standardized variance components as given in Tables 1 and 3 shows that the two models also decompose the phenotypic variance in a similar fashion. Consider the decomposition of FSIQ at age 12.2 years. In the standard model, the standardized components are 0.54 (A), 0.22 (E), and $0.24(\mathrm{C})$. In the alternative model, the standard components are $0.21(\mathrm{~A}), 0.37\left(\mathrm{E}^{*}\right), 0.09(\mathrm{C}$; occasion specific), and $0.33\left(2 \cdot \operatorname{cov}\left(\mathrm{AE}^{*}\right)\right)$. While the models differ in the details of the decomposition, they are identical in terms of the total environmental variance and total genetic variance. The total environmental variance in the standard model equals $0.22(\mathrm{E})+0.24(\mathrm{C})=0.46$ whereas in the alternative model the total environmental variance equals $0.37\left(\mathrm{E}^{*}\right)+0.09(\mathrm{C}$ occasion specific $)=0.46$. Similarly, the total genetic variance within standard model equals $0.54(\mathrm{~A})$, whereas in the alternative model this variance equals $0.21(\mathrm{~A})+0.33\left(2 \cdot \operatorname{cov}\left(\mathrm{AE}^{*}\right)\right)=0.54$, if we treat $2 \cdot \operatorname{cov}\left(\mathrm{AE}^{*}\right)$ as genetic variance [37].

Additionally, we see that the correlation between the environments of the twins shows a similar pattern as the standardized variance component $\mathrm{C}$. For example, consider the correlations in $\mathrm{E}^{*}$ for FSIQ which are 0.63 (5.5 years), 0.29 (6.8 years), 0.30 (9.7 years) and 0.32 (12.2 years), whereas the standardized $\mathrm{C}$ components in the standard model 0.50 (5.5 years), 0.23 (6.8 years), 0.20 (9.7 years) and 0.24 (12.2 years). It should be noted that in the alternative model, after 5.5 years the correlation in $\mathrm{E}^{*}$ is influenced by the initial correlation in environment at time point 1 plus the influence of $\mathrm{Ph}->\mathrm{E}$ transmission over time. The influence this transmission (i.e., the AE correlation in FSIQ) becomes more prominent over time: 0 (5.5 years), 0.30 (6.8 years), 0.53 (9.7 years), and 0.57 (12.2 years). These observations show that traditional heritability estimates can be decomposed in direct and indirect genetic effects. As such, it raises the question of which decomposition (the standard ACE or the AE* with $\mathrm{Ph}->\mathrm{E}$ transmission) leads to greater insight in the developmental process. Here, we provisionally accept the alternative model, as we can utilize the results to answer the hypothetical question: What increases in phenotypic mean at age 12.2 years can we expect from changes in environmental means in combination with changes in $\mathrm{Ph}->\mathrm{E}$ transmission? 
Table 4. $\mathrm{MZ}$ covariance matrix of $\mathrm{A}$ and $\mathrm{E}^{*}$ in the $\mathrm{AE}^{*}$ model of FSIQ with $\mathrm{Ph}-\mathrm{P}$ transmission. These include the $\mathrm{AE}^{*}$ covariance and $\mathrm{AE}^{*}$ correlation within twins (bold) and between twins (bold italics) and the covariance and correlations among the twin environments (italics). Age is given in years.

\begin{tabular}{|c|c|c|c|c|c|c|c|c|c|c|c|c|c|c|c|c|}
\hline \multirow[b]{3}{*}{ Age in years } & \multicolumn{8}{|c|}{ Correlation } & \multicolumn{8}{|c|}{ Covariance } \\
\hline & \multicolumn{4}{|c|}{ A Twin 1} & \multicolumn{4}{|c|}{$E^{*}$ Twin 1} & \multicolumn{4}{|c|}{ A Twin 2} & \multicolumn{4}{|c|}{ E* Twin 2} \\
\hline & 5.5 & 6.8 & 9.7 & 12.2 & 5.5 & 6.8 & 9.7 & 12.2 & 5.5 & 6.8 & 9.7 & 12.2 & 5.5 & 6.8 & 9.7 & 12.2 \\
\hline \multirow{4}{*}{ A twin 1} & 1 & & & & & & & & 31.71 & & & & & & & \\
\hline & 0.86 & 1 & & & & & & & 28.38 & 34.16 & & & & & & \\
\hline & 0.86 & 1.00 & 1 & & & & & & 25.40 & 30.57 & 27.36 & & & & & \\
\hline & 0.86 & 1.00 & 1.00 & 1 & & & & & 22.74 & 27.36 & 24.49 & 21.92 & & & & \\
\hline \multirow{4}{*}{ E twin 1} & 0.00 & 0.00 & 0.00 & 0.00 & 1 & & & & 0.00 & 0.00 & 0.00 & 0.00 & 83.44 & & & \\
\hline & 0.35 & 0.30 & 0.30 & 0.30 & 0.41 & 1 & & & 16.65 & 14.90 & 13.34 & 11.94 & 39.39 & 26.64 & & \\
\hline & 0.50 & 0.53 & 0.53 & 0.53 & 0.20 & 0.43 & 1 & & 23.18 & 25.34 & 22.68 & 20.30 & 18.37 & 22.12 & 23.56 & \\
\hline & 0.53 & 0.59 & 0.59 & 0.59 & 0.09 & 0.30 & 0.47 & 1 & 24.73 & 28.53 & 25.53 & 22.85 & 8.50 & 17.71 & 23.74 & 24.14 \\
\hline \multirow{4}{*}{ A twin 2} & 0.50 & & & & & & & & 63.43 & & & & & & & \\
\hline & 0.43 & 0.50 & & & & & & & 56.77 & 68.32 & & & & & & \\
\hline & 0.43 & 0.50 & 0.50 & & & & & & 50.81 & 61.15 & 54.73 & & & & & \\
\hline & 0.43 & 0.50 & 0.50 & 0.50 & & & & & 45.47 & 54.73 & 48.98 & 43.84 & & & & \\
\hline \multirow{4}{*}{$\mathrm{E}$ twin 2} & 0.00 & 0.00 & 0.00 & 0.00 & 0.63 & & & & 0.00 & 0.00 & 0.00 & 0.00 & 132.40 & & & \\
\hline & 0.22 & 0.19 & 0.19 & 0.19 & 0.36 & 0.29 & & & 26.64 & 23.84 & 21.34 & 19.10 & 45.79 & 92.29 & & \\
\hline & 0.33 & 0.35 & 0.35 & 0.35 & 0.18 & 0.26 & 0.30 & & 35.26 & 38.92 & 34.83 & 31.17 & 20.39 & 36.60 & 78.63 & \\
\hline & 0.36 & 0.40 & 0.40 & 0.40 & 0.09 & 0.21 & 0.31 & 0.32 & 36.54 & 42.44 & 37.98 & 33.99 & 9.14 & 24.79 & 35.90 & 75.39 \\
\hline
\end{tabular}

Table 5. DZ covariance matrix of $A$ and $E^{*}$ in the $A E^{*}$ model of perfIQ with $\mathrm{Ph}->\mathrm{E}$ transmission. These include the $\mathrm{AE}^{*}$ covariance and $\mathrm{AE}^{*}$ correlation within twins (bold italics) and between twins (bold italics) and the covariance and correlations among the twin environments (italics), which mimics the presence of shared variance. Age is given in years.

\begin{tabular}{|c|c|c|c|c|c|c|c|c|c|c|c|c|c|c|c|c|}
\hline \multirow[b]{3}{*}{ Age in years } & \multicolumn{8}{|c|}{ Correlation } & \multicolumn{8}{|c|}{ Covariance } \\
\hline & \multicolumn{4}{|c|}{ A Twin 1} & \multicolumn{4}{|c|}{$E^{*}$ Twin 1} & \multicolumn{4}{|c|}{ A Twin 2} & \multicolumn{4}{|c|}{$E^{*}$ Twin 2} \\
\hline & 5.5 & 6.8 & 9.7 & 12.2 & 5.5 & 6.8 & 9.7 & 12.2 & 5.5 & 6.8 & 9.7 & 12.2 & 5.5 & 6.8 & 9.7 & 12.2 \\
\hline \multirow{4}{*}{ A twin 1} & 1.00 & & & & & & & & 40.87 & & & & & & & \\
\hline & 1.00 & 1.00 & & & & & & & 35.84 & 31.43 & & & & & & \\
\hline & 1.00 & 1.00 & 1.00 & & & & & & 31.43 & 27.57 & 24.18 & & & & & \\
\hline & 0.81 & 0.81 & 0.81 & 1.00 & & & & & 27.57 & 24.18 & 21.20 & 28.64 & & & & \\
\hline \multirow{4}{*}{ E twin 1} & 0.00 & 0.00 & 0.00 & 0.00 & 1.00 & & & & 0.00 & 0.00 & 0.00 & 0.00 & 24.74 & & & \\
\hline & 0.41 & 0.41 & 0.41 & 0.33 & 0.16 & 1.00 & & & 22.72 & 19.93 & 17.48 & 15.33 & 13.12 & 19.40 & & \\
\hline & 0.60 & 0.60 & 0.60 & 0.48 & 0.08 & 0.41 & 1.00 & & 32.40 & 28.41 & 24.92 & 21.85 & 6.94 & 22.46 & 28.10 & \\
\hline & 0.58 & 0.58 & 0.58 & 0.47 & 0.04 & 0.32 & 0.39 & 1.00 & 35.18 & 30.85 & 27.06 & 23.73 & 3.66 & 22.16 & 28.95 & 30.41 \\
\hline
\end{tabular}


Table 5. Cont.

\begin{tabular}{|c|c|c|c|c|c|c|c|c|c|c|c|c|c|c|c|c|}
\hline \multirow[b]{3}{*}{ Age in years } & \multicolumn{8}{|c|}{ Correlation } & \multicolumn{8}{|c|}{ Covariance } \\
\hline & \multicolumn{4}{|c|}{ A Twin 1} & \multicolumn{4}{|c|}{$E^{*}$ Twin 1} & \multicolumn{4}{|c|}{ A Twin 2} & \multicolumn{4}{|c|}{$E^{*}$ Twin 2} \\
\hline & 5.5 & 6.8 & 9.7 & 12.2 & 5.5 & 6.8 & 9.7 & 12.2 & 5.5 & 6.8 & 9.7 & 12.2 & 5.5 & 6.8 & 9.7 & 12.2 \\
\hline \multirow{4}{*}{ A twin 2} & 0.50 & & & & & & & & 81.74 & & & & & & & \\
\hline & 0.50 & 0.50 & & & & & & & 71.69 & 62.87 & & & & & & \\
\hline & 0.50 & 0.50 & 0.50 & & & & & & 62.87 & 55.14 & 48.35 & & & & & \\
\hline & 0.40 & 0.40 & 0.40 & 0.50 & & & & & 55.14 & 48.35 & 42.41 & 57.28 & & & & \\
\hline \multirow{4}{*}{ E twin 2} & 0.00 & 0.00 & 0.00 & 0.00 & 0.27 & & & & 0.00 & 0.00 & 0.00 & 0.00 & 92.61 & & & \\
\hline & 0.23 & 0.23 & 0.23 & 0.19 & 0.12 & 0.16 & & & 40.91 & 35.88 & 31.47 & 27.60 & 16.50 & 119.1 & & \\
\hline & 0.34 & 0.34 & 0.34 & 0.28 & 0.07 & 0.20 & 0.26 & & 56.44 & 49.50 & 43.41 & 38.07 & 8.44 & 47.12 & 108.7 & \\
\hline & 0.34 & 0.34 & 0.34 & 0.27 & 0.03 & 0.18 & 0.24 & 0.23 & 59.87 & 52.50 & 46.05 & 40.38 & 4.32 & 39.36 & 46.24 & 130.0 \\
\hline
\end{tabular}

\section{Can Ph->E Transmission and Changes in Environmental Means Account for the Flynn Effect?}

It has been argued that a shift in environmental means over generations might potentially explain the observed Flynn effect [1]. Note that Dickens and Flynn do not pinpoint any particular environmental influence [1]. We assume that many environmental variables (e.g., nutrition, education, internet access) in combination contribute to the increase in mean IQ. These environmental influences are thought to be novel and uncorrelated with the genotype and IQ.

Traditionally, within the simplex model the mean of the environment $\left(\zeta_{E^{*} i t}\right)$ is assumed to be zero. To incorporate the influence of environmental means in the extended $\mathrm{AE}^{*}$ model with $\mathrm{Ph}->\mathrm{E}$ transmission, we include structured environmental means [38]. We can do this by assigning to the means of the environmental variables $\mathrm{E}^{*}{ }_{1}$ and $\zeta_{\mathrm{E}^{*} \mathrm{t}}$ non-zero values. We retain zero mean genetic variables, but will return to this assumption in the discussion. Given $y_{i t}{ }^{*}=A_{i t}+E^{*}$, the mean of $y_{t}{ }^{*}$ is $m\left(y_{t}{ }^{*}\right)=m\left(E^{*}\right)$. The means are modeled in the MZs and DZs as follows:

$$
\begin{aligned}
& \mathrm{m}\left(\mathrm{E}^{*}{ }_{1 \mathrm{t}}\right)=\beta_{\mathrm{Et}, \mathrm{t}-1} \mathrm{~m}\left(\mathrm{E}^{*}{ }_{1 \mathrm{t}-1}\right)+\alpha_{\mathrm{t}} \mathrm{m}\left(\mathrm{y}^{*}{ }_{1 \mathrm{t}-1}\right)+\gamma_{\mathrm{t}} \mathrm{m}\left(\mathrm{y}^{*}{ }_{2 \mathrm{t}-1}\right)+\mathrm{m}\left(\zeta_{\mathrm{E}^{*} 1 \mathrm{t}}\right) \\
& \mathrm{m}\left(\mathrm{E}^{*}{ }_{2 \mathrm{t}}\right)=\beta_{\mathrm{Et}, \mathrm{t}-1} \mathrm{~m}\left(\mathrm{E}^{*}{ }_{2 \mathrm{t}-1}\right)+\gamma_{\mathrm{t}} \mathrm{m}\left(\mathrm{y}^{*}{ }_{1 \mathrm{t}-1}\right)+\alpha_{\mathrm{t}} \mathrm{m}\left(\mathrm{y}^{*}{ }_{2 \mathrm{t}-1}\right)+\mathrm{m}\left(\zeta_{\mathrm{E}}{ }^{* \mathrm{t}}\right),
\end{aligned}
$$

At time point 1, the mean of IQ will equal the mean of the environment (i.e., $\left.\mathrm{m}\left(\mathrm{y}^{*}{ }_{\mathrm{it}}\right)=\mathrm{m}\left(\mathrm{E}^{*}{ }_{\mathrm{i} 1}\right)=\mathrm{m}\left(\zeta_{\mathrm{E}^{*} \mathrm{i} 1}\right)\right)$. However, due to the impact of IQ on the environment, as defined by via the terms $\alpha_{t} m\left(y^{*}{ }_{1 t-1}\right)$ and $\gamma_{t}$ $\mathrm{m}\left(\mathrm{y}^{*}{ }_{1 \mathrm{t}-1}\right)$, the impact of IQ on the environment ( $\mathrm{Ph}-\mathrm{E}$ transmission) will enhance the environmental effect, via multiplication of the environmental mean. Using Equations (12) and (13), we can evaluate how a shift in environmental means leads to a shift in phenotypic means.

By introducing the environmental means, we can explore numerically the effects on the phenotypic means of changes in environmental means in combination with changes in the $\mathrm{Ph}-\mathrm{P}$ transmission parameters. Using the parameter estimates as obtained in the previous analyses (Table 3), we know $\beta_{\mathrm{Et}, \mathrm{t}-1}=0$. Therefore, within the following simulation, the environmental means are defined to be

$$
\begin{aligned}
& \mathrm{m}\left(\mathrm{E}^{*}{ }_{1 \mathrm{t}}\right)=\alpha_{\mathrm{t}} \mathrm{m}\left(\mathrm{y}^{*}{ }_{1 \mathrm{t}-1}\right)+\gamma_{\mathrm{t}} \mathrm{m}\left(\mathrm{y}^{*}{ }^{\mathrm{t}-1}\right)+\mathrm{m}\left(\zeta_{\mathrm{E}^{*} 1 \mathrm{t}}\right) \\
& \mathrm{m}\left(\mathrm{E}^{*}{ }_{2 \mathrm{t}}\right)=\gamma_{\mathrm{t}} \mathrm{m}\left(\mathrm{y}^{*}{ }_{1 \mathrm{t}-1}\right)+\alpha_{\mathrm{t}} \mathrm{m}\left(\mathrm{y}^{*}{ }_{2 \mathrm{t}-1}\right)+\mathrm{m}\left(\zeta_{\mathrm{E}^{*} 2 \mathrm{t}}\right) .
\end{aligned}
$$

where we assume $\mathrm{m}\left(\zeta_{\mathrm{E}^{* 1} \mathrm{t}}\right)=\mathrm{m}\left(\zeta_{\mathrm{E}^{*} \mathrm{t}}\right)(\mathrm{t}=1 \ldots 4)$, and $\mathrm{m}\left(\zeta_{\mathrm{E}^{*} \mathrm{it}}\right)=\mathrm{m}\left(\zeta_{\mathrm{E} * \mathrm{it}+1}\right)(\mathrm{t}=1 \ldots 3)$. 
In evaluating the degree to which these changes can account for the Flynn effect, we assume that in the 1990s, say, the average of environmental influences relevant to the development of cognitive abilities were more conducive to cognitive development than those in the 1960s. This is consistent with possible improvements in nutrition $[39,40]$, educational practices, parental involvement, and the advantages of increased material wealth $[41,42]$.

In addition, we consider the possibility that positive $\mathrm{Ph}->\mathrm{E}$ transmission was greater in the 1990 s than in the 1960s, i.e., the 1990s society is fairer in that it better facilitates matching of child's phenotypic intelligence to the environment relevant to intelligence. We ask: To what degree do changes in these parameters account for the Flynn effect? To this end, we assume (arbitrarily) that the Ph- $>\mathrm{E}$ transmission parameters $\alpha$ and $\gamma$ in the $1960 \mathrm{~s}$ are $\mathrm{w}_{\alpha \gamma}=1 / 4, \mathrm{w}_{\alpha \gamma}=2 / 4, \mathrm{w}_{\alpha \gamma}=3 / 4$, or $\mathrm{w}_{\alpha \gamma}=4 / 4$ of their 1990s values, where we take the 1990s value to be those observed in the present analysis of FSIQ $(\alpha=0.385$ and $\gamma=0.07)$ and perfIQ $(\alpha=0.482$ and $\gamma=0.037)$. We chose values of the mean $\mathrm{m}\left(\mathrm{E}^{*}{ }_{1}\right)$ equal to $1 / 4,2 / 4$, or $3 / 4$ of the average phenotypic standard deviation as observed in the analysis of FSIQ (14.7) and perfIQ (15.7), and choose the means $\mathrm{m}\left(\zeta_{\mathrm{E}^{*} \mathrm{t}}\right)$ such that the phenotypic mean at age 12.2 years equals to the chosen $\mathrm{m}\left(\mathrm{E}^{*}\right)$, given $\mathrm{w}_{\alpha \gamma}=1 / 4$. The values chosen serve only to obtain an indication of the effect on the phenotypic mean given a relatively large variation in the environmental means and $\mathrm{w}_{\alpha \beta}$.

The results are shown in Tables 6 (FSIQ) and 7 (perfIQ). In the first row of Table 6, we start by setting all means equal to zero (in that case, the value of $\mathrm{w}_{\alpha \gamma}$ is immaterial). We then set the mean of $\mathrm{m}\left(\mathrm{E}^{*}{ }_{1}\right)$ to equal $14.7 / 4=3.675$, one fourth of the observed phenotypic standard deviation, and choose the mean $\mathrm{m}\left(\zeta_{E^{*}}\right)$ to equal 3.26 , so that the phenotypic mean at $\mathrm{t}=4$ (age 12) equals $14.7 / 4$. So, given $\alpha=0.386 / 4$ and $\beta=0.07 / 4$, changing the environmental means from $\mathrm{m}\left(\mathrm{E}^{*}{ }_{1}\right)=0$ and $\mathrm{m}\left(\zeta_{\mathrm{E}^{*}}\right)=0$ to $\mathrm{m}\left(\mathrm{E}_{1}{ }_{1}\right)=14.7 / 4$ and $\mathrm{m}\left(\zeta_{\mathrm{E}^{*} \mathrm{t}}\right)=3.675$, results in an increase in phenotypic mean from 0 to $3.67(1 / 4$ of $14.7 \mathrm{std})$ at age $12.2 \mathrm{y}$. We then ask: Given the values of $\mathrm{m}\left(\mathrm{E}^{*}{ }_{1}\right)=3.675$ and $\mathrm{m}\left(\zeta_{\mathrm{E}^{*}}\right)=3.675$, what is the effect of increasing the parameters $\alpha$ and $\gamma$ (increasing $\mathrm{w}_{\alpha \gamma}$ from $1 / 4$ to 1 ). The answer to this question is contained in the subsequent rows, where we see that the phenotypic mean increases from 0.25 (as chosen) to 0.39 in standard deviation units ( $\mathrm{std}=14.7)$. Note that this increase is due to changes in $\mathrm{Ph}-\mathrm{P}$ transmission only. So, the combination of increasing the environmental means (from zero to 3.67 and 3.26), and increasing the transmission parameters from 0.096 and $0.017\left(\mathrm{w}_{\alpha \gamma}=1 / 4\right)$ to the observed values of 0.385 and $0.070\left(\mathrm{w}_{\alpha \gamma}=1\right)$ increases the phenotypic means by 0.39 standard deviation units. The results in the rest of the table pertain to the greater increases in environmental means (from $1 / 4$ to $2 / 4$ and $3 / 4$ ). For instance, the last four rows pertaining to the largest changes in environmental mean indicate that the increase in environmental means with increasing $\mathrm{Ph}->\mathrm{E}$ transmission parameters results in a maximal increase in the phenotypic means of 1.18 standard deviation units. This demonstrates that changes in the environmental means, reflecting improvements in the environment relevant to FSIQ are boosted by a factor of about 1.57 by the increase in the $\mathrm{Ph}->\mathrm{E}$ transmission parameters $\left(\mathrm{w}_{\alpha \gamma}=1 / 4\right.$ to 1$)$. Table 7 contains similar results pertaining to perfIQ, where the effects are given in average standard deviation units of perfIQ $(\mathrm{std}=15.7)$. Here, the increase in $\mathrm{w}_{\alpha \gamma}$ from $1 / 4-1$ boosts the environmental mean effect by a factor 1.7. These results demonstrate the possible role of $\mathrm{Ph}->\mathrm{E}$ transmission (GE-cov) in the Flynn effect. 
Table 6. Raw phenotypic mean changes (std units) of FSIQ as a function of weight given to the $\mathrm{Ph}->\mathrm{E}$ transmission parameters $\left(\mathrm{w}_{\alpha \gamma}=0.25,0.50,0.75\right)$ and different environmental means. Environmental means at $\mathrm{t}=1$ is defined as a function of standard deviation of FSIQ $\left(\mathrm{sd}_{\mathrm{FSIQ}}=14.7\right.$, Small $=\mathrm{sd}_{\mathrm{FSIQ}} * 0.25$, Medium $=\operatorname{sd}_{\mathrm{FSIQ}} * 0.50$ and Large $\left.=\operatorname{sd}_{\mathrm{FSIQ}} * 0.75\right)$. Environmental means at $t+1$ are calculated according to Equations (14) and (15).

\begin{tabular}{cccc}
\hline \multirow{2}{*}{ Weight Ph- $>$ E Parameters } & \multicolumn{3}{c}{ Increase Environment } \\
\cline { 2 - 4 } & Small & Medium & Large \\
\hline 0.25 & $3.68(0.25)$ & $7.36(0.50)$ & $11.04(0.75)$ \\
0.50 & $4.22(0.29)$ & $8.43(0.57)$ & $12.65(0.86)$ \\
0.75 & $4.90(0.33)$ & $9.80(0.67)$ & $14.70(1.00)$ \\
1 & $5.77(0.39)$ & $11.53(0.78)$ & $17.30(1.18)$ \\
\hline
\end{tabular}

Table 7. Raw phenotypic mean changes (std units) as a function of weight given to the $\mathrm{Ph}->\mathrm{E}$ transmission parameters $\left(\mathrm{w}_{\alpha \gamma}=0.25,0.50,0.75\right)$ and different environmental means. Environmental means at $\mathrm{t}=1$ is defined as a function of standard deviation of perf IQ $\left(\mathrm{sd}_{\text {perflQ }}=15.71\right.$, Small $=\operatorname{sd}_{\text {perflQ }} * 0.25$, Medium $=\operatorname{sd}_{\text {perflQ }} * 0.50$ and Large $\left.=\operatorname{sd}_{\text {perflQ }} * 0.75\right)$. Environmental means at $\mathrm{t}+1$ are calculated according to Equations (14) and (15).

\begin{tabular}{cccc}
\hline \multirow{2}{*}{ Weight Ph->E Parameters } & \multicolumn{3}{c}{ Increase Environment } \\
\cline { 2 - 4 } & Small & Medium & Large \\
\hline 0.25 & $3.93(0.25)$ & $7.85(0.50)$ & $11.78(0.75)$ \\
0.50 & $4.60(0.29)$ & $9.21(0.59)$ & $13.81(0.88)$ \\
0.75 & $5.49(0.35)$ & $11.00(0.70)$ & $16.49(1.05)$ \\
1 & $6.66(0.42)$ & $13.32(0.85)$ & $19.98(1.27)$ \\
\hline
\end{tabular}

\section{Discussion}

The aims of the present paper were to present and apply an longitudinal twin model that includes GE-cov originating in $\mathrm{Ph}->\mathrm{E}$ transmission $[14,18]$, which is consistent with the model proposed by Dickens and Flynn [1], and to determine how $\mathrm{Ph}->\mathrm{E}$ transmission can amplify beneficial (to IQ) environmental changes. We found that the $\mathrm{AE}^{*}$ model including $\mathrm{Ph}->\mathrm{E}$ transmission fitted the data as well as the ACE simplex model [12]. The decomposition of variance in terms of total genetic and environmental effects (where GE-cov is counted as genetic variance [37]) is similar in these models, but the details of the decomposition differ appreciably. For instance, in the standard model, total genetic variance is attributed to genetic effects, whereas in the alternative model well over half of the total genetic variance (genetic variance plus GE-cov) is due to the GE-cov(see Table 3). In addition, in the standard model, shared environment is conceptualized as an independent source of phenotypic individual differences, whereas in the alternative model true shared environmental effects are small and occasion specific. The correlations between the environmental effects of the twins originate in the correlation at $\mathrm{t}=1$ and in $\mathrm{Ph}->\mathrm{E}$ transmission thereafter. Statistically, the alternative model has the disadvantage of lacking orthogonality of the decomposition of variance, which complicates the interpretation of the variance components. However, it has the advantage of being consistent with theoretical notions concerning the role of GE-cov in cognitive development. 
The second aim of this paper was to explore numerically the increases in phenotypic means attributable to changes in environmental means in combination with changes in the $\mathrm{Ph}->\mathrm{E}$ parameters (denoted $\alpha$ and $\gamma$ ). Basing our exploration on changes in environmental means and $\mathrm{Ph}-\mathrm{E}$ transmission parameters, we found that the GE-cov boosted the phenotypic increases in means (due to environmental mean increases) by a factor of 1.57 (FSIQ) to 1.7 (perfIQ). We note that this is the largest effect that we obtained, based on the largest change in the transmission parameters $\left(\mathrm{w}_{\alpha \gamma}=1 / 4\right.$ to $\left.\mathrm{w}_{\alpha \gamma}=1\right)$. We are satisfied, based on our results, that GE-cov can contribute to the Flynn effect, but we cannot be sure about the ultimate effect size (our numerical values are arbitrary). In our numerical exploration, we have assumed that measurement invariance (MI) holds with respect to cohort. However, Wicherts et al. demonstrated that common IQ tests do not display measurement invariance [43]. This poses a psychometric problem, if one wishes to interpret cohort or generation related mean differences in terms of latent variables. However, the lack of MI has no bearing on the possible role of GE-cov in the Flynn effect: Increases in latent environmental (and genetic means) in combination with changes in $\mathrm{Ph}-\mathrm{E}$ transmission parameters may contribute to the Flynn effect, even if the lack of MI complicates the interpretation of increases, over time, in phenotypic means.

We limited our exploration to increases in environmental means. It has been hypothesized that genetic mean increases due to outbreeding (hybrid vigor) is an important contributor to the Flynn effect $[44,45]$. We consider it plausible that outbreeding has resulted in increases in genetic means. For instance, Abdellaoui et al. recently showed that higher IQ is associated with greater internal migration in the Netherlands [46]. They demonstrated that this is associated with lower proportion of runs of homozygosity among higher IQ individuals due to assortative mating among individual of distant geographical origin. Increases in migration are certainly compatible with the interpretation of $\mathrm{Ph}->\mathrm{E}$ transmission as active GE-cov. While increases in genetic means seem plausible, the actual effect size is unlikely to be large [45]. We note that genetic mean increases pose no problem in principle, as they readily can be added to the model [38].

We have limited our analyses to FSIQ and perfIQ, as the Flynn effect is supposed to be stronger in performance IQ. We included FSIQ, as this variable remains of interest, as a good part of the Flynn effect literature is based on FSIQ. The differences between FSIQ and perfIQ in the decomposition of variance are too small to conclude that $\mathrm{Ph}->\mathrm{E}$ transmission is stronger in perfIQ than in FSIQ (see Table 4: Standardized $\operatorname{var}(\mathrm{A}) v s$. standardized $2 * \operatorname{cov}(\mathrm{AE})$ ). This may be due to the fact that FSIQ actually includes perfIQ. The analysis of verbal IQ would be a useful addition [47]. Additionally, we have limited our analyses to age 5-12 years. It would be useful to study cognitive development into late adolescence, to establish the changes, if any, in the $\mathrm{Ph}->\mathrm{E}$ transmission over development. It is well established that shared environmental effects $(C)$ in the standard orthogonal decomposition vanish to essentially zero as children progress into late adolescence and early adulthood. The decline in $\mathrm{C}$ in the standard model predicts a decline in $\mathrm{Ph}-\mathrm{PE}$ transmission, as the latter contributes to correlated environmental effects of the twins (i.e., apparent $C$; see Tables 4 and 5).

We conclude that the $\mathrm{AE}^{*}$ simplex model with $\mathrm{Ph}->\mathrm{E}$ transmission provides a useful alternative to the orthogonal decomposition of the standard ACE simplex model. The model is theoretically well justified, given the hypothesized importance of GE-cov in cognitive development. In addition, it is relevant to the model of Dickens and Flynn [1], which assigns to GE-cov an important role in explaining the Flynn effect. Our numerical exploration demonstrates the possible role of $\mathrm{Ph}-\mathrm{P}$ transmission in 
amplifying increases in environmental means, as suggested by Dickens and Flynn [1]. Although we have not considered increases in genetic means here, we note that $\mathrm{Ph}-\mathrm{P}$ transmission will equally boost such increases.

\section{Acknowledgments}

The study was supported by Spinozapremie (NWO/SPI 56-464-14192); European Research Council Genetics of Mental Illness (ERC-230374); Twin-family database for behavior genetics and genomics studies (NWO 480-04-004); Longitudinal Survey and Panel Funding Application 2008 (NWO-481-08-011); NARSAD; Brain \& Behavior Research Foundation-18633; Genetic and Family influences on Adolescent Psychopathology and Wellness (NWO 463-06-001); A twin-sib study of adolescent wellness (NWO-VENI 451-04-034); The interplay of genetic and environmental factors in the development of anxious depression in children and adults (NWO-VENI grant 916-76-125); Genetic influences on stability and change in psychopathology from childhood to young adulthood (ZonMW 912-10-020); Do our genes pave our way? Modeling GE-covariance, GxE interaction and moderated GE-covariance in longitudinal twin data (NWO 406-12-124).

\section{Author Contributions}

JMdeK, CVD, K-JK, DIB: Conceptualization; CVD, JMdeK, K-JK: Programming, statistical analyses; JMdeK, CVD, K-JK, DIB: Writing and editing; CEMvB, MB, DIB: Data collection and management. 
Appendix I. FIML Estimates of Correlations, Standard Deviations, Means

\begin{tabular}{|c|c|c|c|c|c|c|c|c|}
\hline \multirow[b]{3}{*}{ Age in years } & \multicolumn{8}{|c|}{ FSIQ MZ } \\
\hline & \multicolumn{4}{|c|}{ Twin 1} & \multicolumn{4}{|c|}{ Twin 2} \\
\hline & 5.5 & 6.8 & 9.7 & 12.2 & 5.5 & 6.8 & 9.7 & 12.2 \\
\hline \multirow[t]{8}{*}{ Correlations } & 1 & & & & & & & \\
\hline & 0.661 & 1 & & & & & & \\
\hline & 0.486 & 0.725 & 1 & & & & & \\
\hline & 0.419 & 0.603 & 0.781 & 1 & & & & \\
\hline & 0.770 & 0.669 & 0.584 & 0.552 & 1 & & & \\
\hline & 0.450 & 0.674 & 0.752 & 0.736 & 0.521 & 1 & & \\
\hline & 0.453 & 0.641 & 0.840 & 0.753 & 0.534 & 0.797 & 1 & \\
\hline & 0.453 & 0.577 & 0.759 & 0.802 & 0.612 & 0.665 & 0.760 & 1 \\
\hline Standard deviations & 14.13 & 15.03 & 17.06 & 15.35 & 14.56 & 15.59 & 17.37 & 15.05 \\
\hline \multirow[t]{2}{*}{ Means } & 109.76 & 104.60 & 104.06 & 98.24 & 108.92 & 101.63 & 104.68 & 99.57 \\
\hline & \multicolumn{8}{|c|}{ FSIQ DZ } \\
\hline \multirow[t]{8}{*}{ Correlations } & 1 & & & & & & & \\
\hline & 0.603 & 1 & & & & & & \\
\hline & 0.477 & 0.662 & 1 & & & & & \\
\hline & 0.471 & 0.673 & 0.737 & 1 & & & & \\
\hline & 0.641 & 0.299 & 0.284 & 0.259 & 1 & & & \\
\hline & 0.421 & 0.482 & 0.366 & 0.333 & 0.505 & 1 & & \\
\hline & 0.225 & 0.322 & 0.481 & 0.357 & 0.383 & 0.623 & 1 & \\
\hline & 0.246 & 0.396 & 0.470 & 0.500 & 0.345 & 0.626 & 0.706 & 1 \\
\hline Standard deviations & 14.37 & 14.66 & 13.92 & 14.03 & 15.54 & 14.27 & 14.34 & 13.69 \\
\hline Means & 108.69 & 104.12 & 105.56 & 100.21 & 108.65 & 104.54 & 105.89 & 99.45 \\
\hline
\end{tabular}




\begin{tabular}{|c|c|c|c|c|c|c|c|c|}
\hline \multirow[b]{3}{*}{ Age in years } & \multicolumn{8}{|c|}{ perfIQ MZ } \\
\hline & \multicolumn{4}{|c|}{ Twin 1} & \multicolumn{4}{|c|}{ Twin 2} \\
\hline & 5.5 & 6.8 & 9.7 & 12.2 & 5.5 & 6.8 & 9.7 & 12.2 \\
\hline \multirow[t]{8}{*}{ Correlations } & 1 & & & & & & & \\
\hline & 0.723 & 1 & & & & & & \\
\hline & 0.667 & 0.726 & 1 & & & & & \\
\hline & 0.674 & 0.635 & 0.696 & 1 & & & & \\
\hline & 0.697 & 0.643 & 0.625 & 0.603 & 1 & & & \\
\hline & 0.628 & 0.722 & 0.733 & 0.654 & 0.655 & 1 & & \\
\hline & 0.611 & 0.653 & 0.754 & 0.670 & 0.573 & 0.762 & 1 & \\
\hline & 0.722 & 0.649 & 0.709 & 0.741 & 0.640 & 0.690 & 0.669 & 1 \\
\hline Standard deviations & 14.35 & 16.92 & 17.83 & 16.72 & 15.68 & 18.34 & 16.51 & 18.65 \\
\hline \multirow[t]{2}{*}{ Means } & 99.52 & 102.72 & 103.60 & 98.52 & 97.88 & 102.21 & 104.74 & 99.11 \\
\hline & \multicolumn{8}{|c|}{ perfIQ DZ } \\
\hline \multirow[t]{8}{*}{ Correlations } & 1 & & & & & & & \\
\hline & 0.573 & 1 & & & & & & \\
\hline & 0.616 & 0.661 & 1 & & & & & \\
\hline & 0.571 & 0.685 & 0.618 & 1 & & & & \\
\hline & 0.491 & 0.261 & 0.239 & 0.344 & 1 & & & \\
\hline & 0.435 & 0.386 & 0.374 & 0.320 & 0.492 & 1 & & \\
\hline & 0.416 & 0.305 & 0.430 & 0.334 & 0.517 & 0.708 & 1 & \\
\hline & 0.353 & 0.376 & 0.325 & 0.396 & 0.439 & 0.535 & 0.601 & 1 \\
\hline Standard deviations & 13.40 & 15.97 & 14.66 & 16.80 & 13.55 & 15.92 & 15.86 & 16.07 \\
\hline Means & 99.36 & 104.88 & 105.26 & 101.03 & 99.45 & 104.89 & 105.10 & 100.58 \\
\hline
\end{tabular}




\section{Conflicts of Interest}

The authors declare no conflict of interest.

\section{References}

1. Dickens, W.T.; Flynn, J.R. Heritability estimates versus large environmental effects: The IQ paradox resolved. Psychol. Rev. 2001, 108, 346-369.

2. Lynn, R.; Hampson, S.L. The rise of national intelligence: Evidence from Britain, Japan and the USA. Personal. Individ. Differ. 1986, 7, 23-32.

3. Flynn, J.R. Massive IQ gains in 14 nations: What IQ tests really measure. Psychol. Bull. 1987, 101, 171-191.

4. Scarr, S. Developmental theories for the 1990s: Development and Individual differences. Child Dev. 1992, 63, 1-19.

5. Scarr, S.; McCartney, K. How people make their own environments: A theory of genotype $\rightarrow$ environment effects. Child Dev. 1983, 54, 424-435.

6. Plomin, R.; DeFries, J.C.; Loehlin, J.C. Genotype-environment interaction and correlation in the analysis of human behavior. Psychol. Bull. 1977, 84, 309-322.

7. Jensen, A.R. The G Factor: The Science of Mental Ability; Praeger Publishers: Westport, CT, USA, 1998, p. 179.

8. Eaves, L.J. The effect of cultural transmission on continuous variation. Heredity 1976, 37, 41-57.

9. Eaves, L.J.; Last, K.; Martin, N.G.; Jinks, J.L. A progressive approach to non-additivity and genotype-environmental covariance in the analysis of human differences. Br. J. Math. Stat. Psychol. 1977, 30, 1-42.

10. Fulker, D.W.; DeFries, J.C. Genetic and environmental transmission in the Colorado Adoption Project: Path analysis. Br. J. Math. Stat. Psychol. 1983, 36, 175-188.

11. Loehlin, J.C.; Horn, J.M.; Willerman, L. Heredity, environment, and IQ in the Texas Adoption Project. In Intelligence, Heredity and Environment; Sternberg, R.J., Grigorenko, E., Eds.; Harvard University Press: Cambridge, MA, USA, 1997; pp. 105-125.

12. Boomsma, D.I.; Molenaar, P.C.M. The genetic analysis of repeated measures. I. Simplex models. Behav. Genet. 1987, 17, 111-123.

13. Hewitt, J.K; Eaves, L.J.; Neale, M.C.; Meyer, J.M. Resolving Causes of Developmental Continuity or “Tracking." I. Longitudinal Twin Studies During Growth. Behav. Genet. 1988, 18, 133-151.

14. Eaves, L.J.; Long, J.; Heath, A.C. A theory of developmental change in quantitative phenotypes applied to cognitive development. Behav. Genet. 1986, 16, 143-162.

15. Martin, N.G.; Eaves, L.J. The genetical analysis of covariance structure. Heredity 1977, 38, 79-95.

16. Jöreskog, K.G. Estimation and testing of simplex models. Br. J. Math. Stat. Psychol. 1970, 23, 121-145.

17. Eaves, L.J. A model for sibling effects in man. Heredity 1976, 36, 205-214.

18. Carey, G. Sibling imitation and contrast effects. Behav. Genet. 1986, 16, 319-341.

19. De Kort, J.M.; Dolan, C.V.; Boomsma, D.I. Accommodation of GE-covariance in a longitudinal twin design. Neth. J. Psychol. 2012, 67, 81-90. 
20. Dolan, C.V.; de Kort, J.M.; van Beijsterveldt, C.E.M.; Bartels, M.; Boomsma, D.I. GE Covariance through phenotype to environment transmission: An assessment in longitudinal twin data. Behav. Genet. 2014, 44, 240-253.

21. Boomsma, D.I.; Vink, J.M.; van Beijsterveldt, T.C.; de Geus, E.J.; Beem, A.L.; Mulder, E.J.; Derks, E.M.; Riese, H.; Willemsen, G.A.; Bartels, M.; et al. Netherlands twin register: A focus on longitudinal research. Twin Res. 2002, 5, 401-406.

22. Boomsma, D.I.; de Geus, E.J.; Vink, J.M.; Stubbe, J.H.; Distel, M.A.; Hottenga, J.J.; Posthuma, D.; van Beijsterveldt, T.C.; Hudziak, J.J.; Bartels, M.; et al. Netherlands Twin Register: From twins to twin families. Twin Res. Hum. Genet. 2006, 9, 849-857.

23. Van Beijsterveldt, C.E.M.; Groen-Blokhuis, M.; Hottenga, J.J.; Franic, S.; Hudziak, J.J.; Lamb, D. ; Huppertz, C.; de Zeeuw, E.; Nivard, M.; Schutte, N.; et al. The Young Netherlands Twin Register (YNTR): Longitudinal Twin and Family Studies in Over 70,000 Children. Twin Res. Hum. Genet. 2013, 16, 252-267.

24. Bleichrodt, N.; Drenth, P.J.D.; Zaal, J.N.; Resing, W.C.M. Revisie Amsterdamse Kinder Intelligentie Test (Revised Amsterdam Child Intelligence Test); Swets and Zeitlinger B.V.: Lisse, The Netherlands, 1984.

25. Van Haasen, P.P.; de Bruyn, E.E.J.; Pijl, Y.J.; Poortinga, Y.H.; Lutje-Spelberg, H.C.; Vander Steene, G.; Coetsier, P.; Spoelders-Claes, R.; Stinissen, J. Wechsler Intelligence Scale for Children-Revised, Dutch Version; Swets \& Zetlinger B.V.: Lisse, The Netherlands, 1986.

26. Wechsler, D.; Kort, W.; Compaan, E.L.; Bleichrodt, N.; Resing, W.C.M.; Schittkatte, M. Wechsler Intelligence Scale for Children-Third edition. Dutch version; Swets and Zeitlinger: Lisse, The Netherlands, 2002.

27. Sattler, J.M. Assessment of Children's Intelligence Andspecial Abilities; Allyn and Bacon, Inc.: Boston, MA, USA, 1982.

28. Sattler, J.M. Assessment of Children: WISC-III and WPPSI-R Supplement; Jerome M Sattler: La Mesa, CA, USA, 1992.

29. Pijl, Y.J.; Hofman, R.H.; Bleichrodt, N.; Resing, W.C.M.; Lutje-Spelberg, H.; Bruijn, E.; de Zaal, J.N. Vergelijkbaarheid van de WISC-R en RAKIT. (Comparability of the WISC-R and RAKIT). Research Instituut voor Onderwijs in het Noorden, Vrije Universiteit: Amsterdam, The Netherlands, 1984.

30. Muthén, L.K.; Muthén, B.O. Mplus User's Guide. 5th ed.; Muthén \& Muthén: Los Angeles, CA, USA, 2007.

31. Schermelleh-Engel, K.; Moosbrugger, H.; Müller, H. Evaluating the fit of structural equation models: Test of significance and descriptive goodness-of-fit measures. Methods Psychol. Res.-Online 2003, 8, $23-74$.

32. Haworth, C.M.A.; Wright, M.J.; Luciano, M.; Martin, N.G.; de Geus, E.J.; van Beijsterveldt, C.E.; Bartels, M.; Posthuma, D.; Boomsma, D.I.; Davis, O.S.; et al. The heritability of general cognitive ability increases linearly from childhood to young adulthood. Mol. Psychiatry 2010, 15, 1112-1120.

33. Hoekstra, R.A.; Bartels, M.; Boomsma, D.I. Longitudinal genetic study of verbal and nonverbal IQ from early childhood to young adulthood. Learn. Individ. Differ. 2007, 17, 97-114. 
34. Petrill, S.A.; Hewitt, J.K.; Cherny, S.S.; Lipton, P.A.; Plomin, R.; Corley, R.; DeFries, J.C. Genetic and environmental contributions to general cognitive ability through the first 16 years of life. Dev. Psychol. 2004, 40, 805-812.

35. Bartels, M.; Rietveld, M.J.H.; van Baal, G.C.M.; Boomsma, D.I. Genetic and environmental influences on the development of intelligence. Behav. Genet. 2002, 32, 237-249.

36. Cardon, L.R.; Fulker, D.W.; DeFries, J.C. Continuity and change in general cognitive ability from 1 to 7 years of age. Dev. Psychol. 1992, 28, 64-73.

37. Falconer, D.S.; Mackay, T.F.C. Introduction to Quantitative Genetics, 4th ed.; Addison Wesley Longman: New York, NY, USA, 1996.

38. Dolan, C.V.; Molenaar, P.C.M.; Boomsma, D.I. Simultaneous genetic analysis of longitudinal means and covariance structure in the simplex model using twin data. Behav. Genet. 1991, 21, 49-65.

39. Lynn, R. The role of nutrition in secular increases of intelligence. Personal. Individ. Differ. 1990, 11, 273-285.

40. Lynn, R. What has caused the Flynn effect? Secular increases in the Development Quotients of infants. Intelligence 2009, 37, 16-24.

41. Williams, W.M. Are we raising smarter children today? School and home-related influences on IQ. In The Rising Curve: Long-Term Gains in IQ and Related Measures; Neisser, U., Ed.; American Psychological Association: Washington, DC, USA, 1998; pp. 125-154.

42. Flynn, J.R. IQ gains over time: Toward finding the causes. In The Rising Curve: Long-Term Gains in IQ and Related Measures; Neisser, U., Ed.; American Psychological Association: Washington, DC, USA, 1998; pp. 25-66.

43. Wicherts, J.M.; Dolan, C.V.; Hessen, D.J.; Oosterveld, P.; van Baal, G.C.M.; Boomsma, D.I.; Span, M.M. Are intelligence tests measurement invariant over time? Investigating the nature of the Flynn effect. Intelligence 2004, 32, 509-537.

44. Mingroni, M.A. Resolving the IQ paradox: Heterosis as a cause of the Flynn effect and other trends. Psychol. Rev. 2007, 114, 806-829.

45. Woodley, M.A. Heterosis Doesn't Cause the Flynn Effect: A Critical Examination of Mingroni (2007). Psychol. Rev. 2011, 118, 689-693.

46. Abdellaoui, A.; Hottenga, J.-J.; Willemsen, G.; Bartels, M.; van Beijsterveldt, T.; Ehli, E.A.; Davies, G.E.; Brooks, A; Sullivan, P.F.; Penninx, B.J.W.H.; et al. Educational Attainment Influences Genetic Variation through Migration and Assortment. submitted for publication.

47. Kan, K.-J.; Wicherts, J.M.; Dolan, C.V.; van der Maas, H.L.J. On the Nature and Nurture of Intelligence and Specific Cognitive Abilities: The More Heritable, the More Culture Dependent. Psychol. Sci. 2012, 24, 2420-2428.

(C) 2014 by the authors; licensee MDPI, Basel, Switzerland. This article is an open access article distributed under the terms and conditions of the Creative Commons Attribution license (http://creativecommons.org/licenses/by/3.0/). 